\title{
Sex-Dependent Effects of Cannabis and Cannabinoids: A Translational Perspective
}

\author{
Ziva D Cooper ${ }^{\star, 1}$ and Rebecca M Craft ${ }^{2}$ \\ ${ }^{1}$ Division on Substance Abuse, New York State Psychiatric Institute and Department of Psychiatry, Columbia University \\ Medical Center, New York, NY, USA; ${ }^{2}$ Department of Psychology, Washington State University, Pullman, WA, USA
}

Recent policy changes have led to significant increases in the use of cannabis for both medical and recreational purposes. Although men are more likely to endorse past month cannabis use and are more frequently diagnosed with Cannabis Use Disorder relative to women, a growing proportion of medical cannabis users are reported to be women. The increased popularity of cannabis for medical purposes and the narrowing gap in prevalence of use between men and women raises questions regarding sex-dependent effects related to therapeutic efficacy and negative health effects of cannabis and cannabinoids. The objective of this review is to provide a translational perspective on the sex-dependent effects of cannabis and cannabinoids by synthesizing findings from preclinical and clinical studies focused on sex comparisons of their therapeutic potential and abuse liability, two specific areas that are of significant public health relevance. Hormonal and pharmacological mechanisms that may underlie sex differences in the effects of cannabis and cannabinoids are highlighted.

Neuropsychopharmacology Reviews (20 I8) 43, 34-5I; doi:10.1038/npp.2017.140; published online 16 August 2017

\section{INTRODUCTION}

Over the last two decades, the policy landscape of cannabis legalization for medical and recreational use has undergone significant changes in the U.S. California was the first state to legalize the use of cannabis for medical purposes in 1996. Since then, medical cannabis has been legalized in 28 states and the District of Columbia for a multitude of indications that vary from state to state (MPP (Marijuana Policy Project), 2016). These indications include chronic pain and chemotherapy-induced nausea, for which there is substantial evidence supporting the clinical utility of cannabis and cannabinoids (chemical constituents of the cannabis plant and synthetic compounds), to other indications that lack strong scientific support from randomized clinical trials, including psychopathologies (anxiety and post-traumatic stress disorder (PTSD)), neurological disorders (Tourette syndrome, Parkinson's and Huntington's Disease), and other health conditions (eg, irritable bowel syndrome) (National Academies of Sciences, 2017). As of 2016, 8 states and the District of Columbia have also legalized cannabis for

\footnotetext{
${ }^{*}$ Correspondence: $\operatorname{Dr}$ ZD Cooper, Division on Substance Abuse, New York State Psychiatric Institute and Department of Psychiatry, Columbia University Medical Center, Columbia University Medical Center, 1051 Riverside Drive, Unit 120, New York, NY 10032, USA, Tel: +646 774 6158, Fax: +646 774 6141, E-mail: zc2160@cumc.columbia.edu Received 8 March 2017; revised 14 June 2017; accepted 27 June 2017; accepted article preview online 17 July 2017
}

recreational use (NCSL (National Conference of State Legislatures), 2017). With the growing acceptance of cannabis use for medical and recreational purposes have come widespread changes in cannabis availability, decreases in perceived risk, and expanding motivations for use (Hasin et al, 2015; Compton et al, 2017). Rates of cannabis use and problematic cannabis use (ie, cannabis use disorder; CUD) have also increased (Hasin et al, 2015); for example, pastmonth cannabis use increased from $6.2 \%$ to $8.3 \%$ between 2002 and 2015 (Center for Behavioral Health Statistics and Quality, 2016). Although epidemiological reports consistently demonstrate that men use cannabis more frequently than women (Substance Abuse and Mental Health Services Administration, 2014a), men seek treatment for cannabis use more often than women (Substance Abuse and Mental Health Services Administration, 2014b), and men are at higher risk for developing CUD (Stinson et al, 2006), a growing number of women report cannabis use for medical purposes (McConnell et al, 2014; Finseth et al, 2015; RyanIbarra et al, 2015). This increase in medical cannabis use by women raises the question of whether its therapeutic efficacy differs as a function of sex. It also raises concerns about the increased susceptibility to developing CUD in women, who show an accelerated progression from initiation of cannabis use to problematic use relative to men, called the 'telescoping effect' (Hernandez-Avila et al, 2004; Ehlers et al, 2010; Schepis et al, 2011). Given the widespread use of cannabis for both medical and recreational purposes, and the emerging 
TABLE 1 Studies of Sex Differences in Acute Analgesic Effects of Cannabinoids

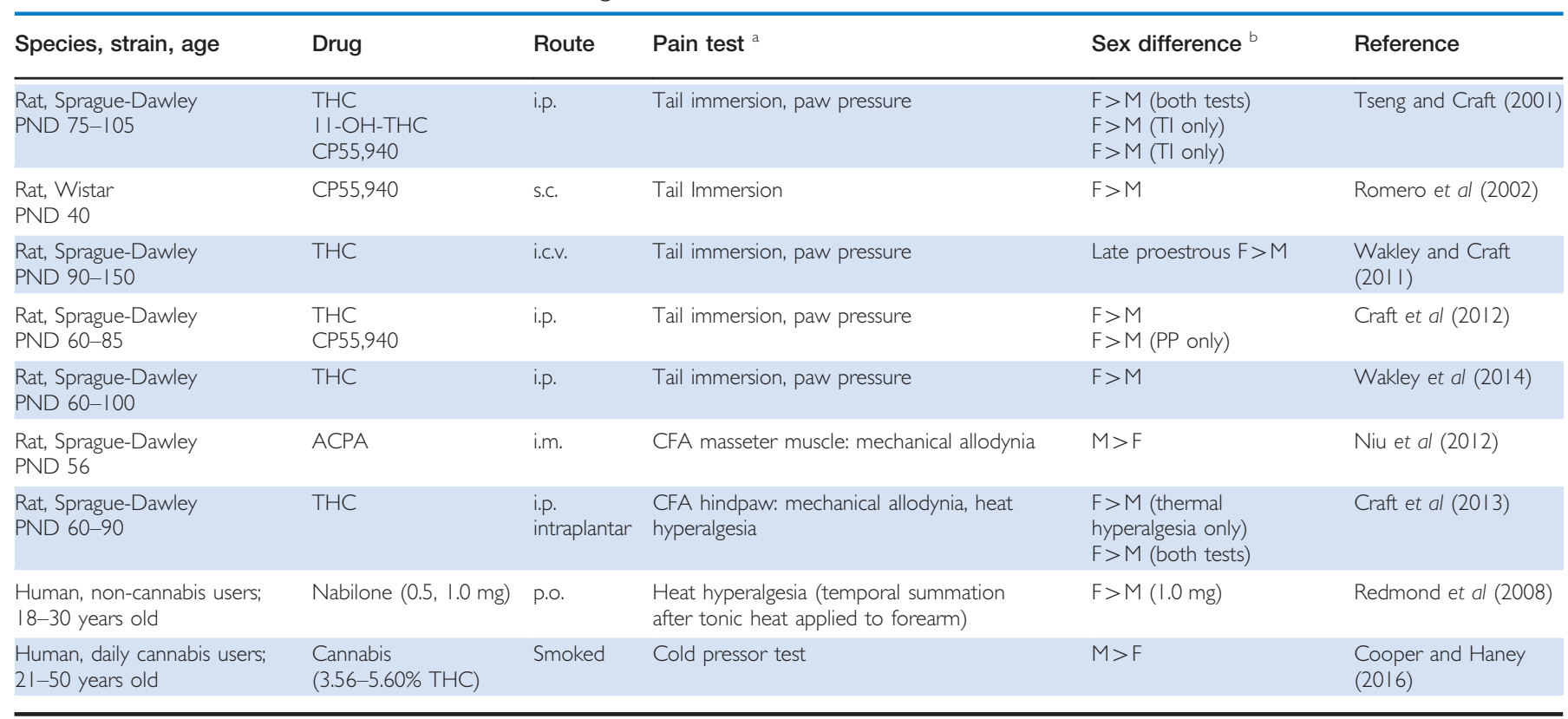

${ }^{a}$ Complete Freund's adjuvant (a model of persistent inflammatory pain). ${ }^{b} \mathrm{~F}>\mathrm{M}$ : drug was significantly more potent, or more effective (at one or more doses) in females compared to males; M>F: drug was significantly more potent, or more effective (at one or more doses) in males compared to females.

trend of more women using cannabis and cannabis-derived products, identifying potential sex differences in the therapeutic effects and risks associated with cannabis use is a public health imperative.

This review synthesizes findings from preclinical (animal) and clinical (human) sex difference studies guided by epidemiological findings that underscore two significant public health issues arising from changing legislation regarding cannabis for medical and recreational use: therapeutic potential and abuse liability. End points that correspond to cannabis's and cannabinoids' potential therapeutic utility focus primarily on neurobiological and behavioral/psychological effects rather than on other physiological End points such as cancer biology and immunology. Literature addressing the effects of adolescent cannabinoid exposure on adult behaviors and cannabinoid sensitivity is not included in this review, nor is the clinical literature on sex differences in cannabis use and brain structure, as these topics have been recently reviewed elsewhere (eg, Viveros et al, 2011, 2012; Ketcherside et al, 2016; Dow-Edwards and Silva, 2017). However, a few sex difference studies examining acute cannabinoid effects in adolescent rats (commonly defined as post-natal day (PND) 28-42, with males maturing slightly later than females (Spear, 2000)) are included, as these results suggest that sexual differentiation of cannabinoid sensitivity may occur well before adulthood for some cannabinoid effects. Pharmacological (eg, cannabinoid metabolism and cannabinoid receptor density) and hormonal mechanisms that may underlie sex differences in cannabinoid effects are briefly reviewed.

\section{POTENTIAL THERAPEUTIC EFFECTS OF CANNABIS AND CANNABINOIDS}

\section{Preclinical Evidence for Sex-Dependent Effects}

Analgesia. Given the demonstrated pain-relieving effects of cannabinoids in clinical trials (Lynch and Ware, 2015) and the commonly reported use of cannabis to reduce chronic pain (Bonn-Miller et al, 2014; Cuttler et al, 2016), most preclinical sex difference studies published to date have focused on determining whether cannabinoids are equipotent and -efficacious analgesics in females $v s$ males. Details of animal and human studies are shown in Table 1. Cannabinoids act at two types of cannabinoid receptors 1 (CB1) and 2 (CB2), with many addiction-related and therapeutic effects known to be due to actions at the CB1 receptor (Pertwee, 2008). In animals, several cannabinoid receptor agonists that act at the $\mathrm{CB} 1$ receptor, including THC (the primary psychoactive constituent of cannabis), its primary active metabolite 11-OH-THC, and the synthetic cannabinoid CP55,940 have been shown to be more potent in female compared to male rats on tests of acute thermal and mechanical pain (Tseng and Craft, 2001; Romero et al, 2002; Craft et al, 2012). Few cannabinoids have been compared in females $v s$ males using models of persistent pain, which are likely to be more predictive of cannabinoid analgesic potential in humans. In the complete Freund's adjuvant (CFA) model of paw inflammatory pain, systemically administered THC produced greater anti-allodynic or anti-hyperalgesic effects in female than in male rats, when tested 1, 3, or 7 days after the induction of pain (Craft et al, 2013). Local (intraplantar) THC administered to CFA- 
treated female and male rats also produced greater antiallodynic and anti-hyperalgesic effects in females, suggesting that sex differences in peripheral cannabinoid function contribute to sex differences in cannabinoid antinociception. Given the consistently greater antinociceptive effect of THC in female rats, surprisingly, THC's anti-edema effect in the CFA model was significantly greater in males (Craft et al, 2013). One other study has reported a sex difference in peripheral antinociceptive effects of a cannabinoid: using a model of orofacial pain in which CFA is injected into the masseter muscle, a CB1-selective agonist was a substantially more potent and efficacious anti-allodynic agent in male rats compared to females (Niu et al, 2012). At this point it is unclear whether the discrepant sex difference between the two studies of peripheral antinociception is related to the selectivity of the cannabinoid, the locus of the pain, or some other methodological difference. Additionally, we do not yet know whether sex differences in cannabinoid antinociception occur at other levels of the neuraxis, for various types of pain. One study demonstrated greater intracerebroventricular (i.c.v.) THC-induced antinociception against acute thermal pain in late proestrous female rats compared to males (Wakley and Craft, 2011), suggesting that a second locus of sex differences is supraspinal. Although intrathecal cannabinoids can be effective analgesics in male ( $\mathrm{Gu}$ et al, 2011; Brownjohn and Ashton, 2012) and female (Cui et al, 2011) rats or mice, we are not aware of any studies comparing spinal cannabinoid antinociception between males and females of any species.

Anxiolysis. Surveys suggest that over 50\% of medical cannabis users are using cannabis to reduce anxiety/stress (Web and Web, 2014; Cuttler et al, 2016). In animals, demonstrating anxiolytic effects of cannabinoids has been challenging, perhaps because cannabinoid effects on anxietylike behavior are dose-dependent, with lower doses tending to be anxiolytic and higher doses tending to be anxiogenic (eg, Rubino et al, 2007, 2008). Furthermore, animal studies typically involve un-signaled, non-contingent cannabinoid administration by the experimenter, which is presumably stressful compared to self-administration, the mode of cannabinoid intake by humans seeking to reduce anxiety/ stress. We found only one published study that included a comparison of cannabinoid effects on anxiety-like behavior in adult (PND60 or older) male vs female rats: on the elevated plus-maze, a moderate dose of THC $(2 \mathrm{mg} / \mathrm{kg})$ increased closed arm time and decreased stretch-attend postures (peering out to open arms from closed arms) in female but not male rats, suggesting increased anxiety-like behavior in females only (Macúchová et al, 2016). Several studies have examined acute cannabinoid effects on anxietylike behavior in adolescent female $v s$ male rats, with variable results: for example, the synthetic cannabinoid CP55,940 was more potent in PND44 females than males in increasing anxiety-like behavior on the elevated plus-maze (Marco et al, 2006), whereas $2 \mathrm{mg} / \mathrm{kg}$ THC was anxiolytic in both sexes tested on PND35 (Harte-Hargrove and Dow-Edwards, 2012).
Silva et al (2016) recently demonstrated that pre-pubertal male and female rats were more sensitive to the anxiolytic effects of $3 \mathrm{mg} / \mathrm{kg}$ THC than post-pubertal rats, and they note that the two sexes do not reach puberty at the same time so that testing both sexes on the same PND may contribute to the inconsistency in sex differences and drug results across studies. Cannabinoid effects on fear- and anxiety-like behaviors can also be test-dependent (Simone et al, 2015). Thus, future research is needed to determine whether sex differences observed to date in the effects of cannabinoids on anxiety are consistent across a broader range of ages, drug doses, and behavioral tests in animals, and of course, whether there are sex differences in the effects of cannabis and cannabinoids on anxiety in humans.

Other potential therapeutic effects for which there are not yet any analyses by sex. While clinical literature suggests that cannabinoids have demonstrated therapeutic effects for the treatment of auto-immune disorders (Ware et al, 2010; Notcutt, 2015; Katchan et al, 2016; Katz et al, 2016), there are no sex difference studies of cannabinoid effects in animal models of auto-immune disease, despite single-sex studies demonstrating promising results (eg, Malfait et al, 2000; Gui et al, 2015; Moreno-Martet et al, 2015). Given that autoimmune disorders are more prevalent in women than men (Klein and Flanagan, 2016), determining whether the greater acute cannabinoid effects observed in female rodents compared to males on some relevant End points (eg, inflammatory pain) extend to models of auto-immune disease is warranted.

Adverse effects. In a review of adverse effects of medical cannabinoid use, Wang et al, 2008 note that nearly 97\% of adverse events reported across 31 studies (including 23 randomized controlled trials) were not serious. The most common non-serious adverse effect was dizziness, followed by gastrointestinal complaints such as nausea/vomiting. Dizziness has not been assessed in animal studies. However, motoric effects are frequently assessed in animal studies of cannabinoid effect, and it is likely that dizziness contributes to altered movement. Cannabinoids such as THC, 11-OHTHC, and CP55,940 have been reported to be more potent in decreasing spontaneous locomotor activity and lever-pressing, and increasing catalepsy in adult female rats compared to males (Tseng and Craft, 2001; Craft et al, 2012; Weed et al, 2016; Wiley et al, 2017). Sex differences in motoric effects of the synthetic cannabinoid agonists WIN55,212-2, CP47,497, and JWH018 were smaller and not statistically significant (Wiley et al, 2017). Greater decreases in locomotor activity have also been reported in adolescent female compared to male rats given CP55,940 (Llorente-Berzal et al, 2011) and THC (Harte and Dow-Edwards, 2010); however, the sex difference with THC is not always observed and may depend on the age at which young rats are tested, as well as procedural factors (Harte and Dow-Edwards, 2010; HarteHargrove and Dow-Edwards, 2012; Wiley et al, 2007). Only one sex difference study in rats has reported a significant 
THC-induced increase in locomotor activity, and this was observed in females only, at the lowest THC dose tested (Wiley and Burston, 2014). In mice, which are more likely than rats to show cannabinoid-induced increases in locomotor activity, females but not males showed THC-induced increases in locomotion (Wiley, 2003). Overall, rodent studies indicate that females may be more sensitive than males to the effects of cannabinoids on movement.

In regard to cannabinoid-elicited nausea, Hempel et al (2017) showed that THC was more potent and efficacious in female rats compared to males in decreasing saccharin consumption in a conditioned taste aversion procedure, suggesting that females are more sensitive than males to the aversive effects of THC, or females were better than males at learning the drug-taste association (which the authors concluded may be the case). Interestingly, considerable animal research suggests that cannabinoid treatment could be useful for alleviating chemotherapy-induced nausea and vomiting (Rock and Parker, 2016). Given that women may be more susceptible than men to chemotherapy-induced nausea (Hilarius et al, 2012), sex comparisons of cannabinoids' anti-nausea and anti-emetic effects in animal studies (and analysis of results by sex in human studies) are warranted.

\section{Clinical Evidence of Sex-Dependent Effects}

Survey/self-report data obtained from medical cannabis dispensaries. Although rates of cannabis use are consistently higher among men, data from surveys of medical cannabis users demonstrate that the gender gap is narrowing. In 20072008 , close to $40 \%$ of chronic pain patients who sought legal qualification for medical cannabis to help manage their pain in Washington State were women (Aggarwal et al, 2009). In a recent survey of 1000 patients diagnosed with a rheumatic condition, nearly half of respondents who reported of medical cannabis to treat symptoms were women (SteMarie et al, 2016). These demographics are similar for other patient populations who use medical cannabis to alleviate symptoms other than pain. For instance, over $50 \%$ of Israeli cancer patients who received a permit for medical cannabis to manage appetite, weakness, nausea, and pain were women (Waissengrin et al, 2015). Men and women appear to use medical cannabis for different reasons. A survey of cannabis users found that of those using cannabis for medical purposes, women were more likely than men to report that they used it to help alleviate anxiety, nausea, anorexia, irritable bowel syndrome, and headache (Cuttler et al, 2016). Significant differences in methods of use also emerged, with more women than men reporting using edible cannabis preparations, whereas men more frequently reported using joints, blunts, vaporizers, and concentrates (Cuttler et al, 2016). These survey findings demonstrate that a significant proportion of the population using medical cannabis to treat specific symptoms are women, however, sex comparisons of self-reported efficacy of cannabis and cannabis-derived products are limited. One recent survey on perceived efficacy of cannabis to treat a variety of medical conditions found that men reported more relief from headache relative to women (Cuttler et al, 2016). Data regarding self-reported efficacy of medical cannabis for other symptoms are not typically analyzed by sex.

Clinical studies. The potential clinical efficacy of cannabis and cannabinoids for various therapeutic indications is supported by findings from randomized, double-blind, and placebo-controlled studies. These studies assessed a range of therapeutic End points as a function of treatment with various CB1 agonists, including oral THC (dronabinol), nabilone, or cannabis containing THC, and various routes of administration including smoked, vaporized, and oral. However, few of these studies speak to the possible sexdependent nature of cannabis and cannabinoid effects, with most testing only one sex or not including sex as a factor in data analysis. This is most evident for studies examining the analgesic effects of cannabinoids in patient populations for various types of pain, including cancer pain (Noyes et al, 1975), chronic non-cancer pain (Issa et al, 2014; Ware et al, 2015), chronic neuropathic pain (Karst et al, 2003), multiple sclerosis-associated pain (Svendsen et al, 2004; Rog et al, 2007), HIV-associated neuropathy (Abrams et al, 2007; Ellis et al, 2009), postoperative pain (Buggy et al, 2003), chronic headache (Pini et al, 2012), post-traumatic or postsurgical neuropathic pain (Ware et al, 2010), neuropathic pain from spinal cord injury (Wilsey et al, 2016), and diabetic neuropathy (Wallace et al, 2015). This is also the case for most laboratory investigations of cannabinoid-induced analgesia in healthy populations (Greenwald and Stitzer, 2000; Naef et al, 2003; Wallace et al, 2007; Kraft et al, 2008; Lee et al, 2013b). Therapeutic effects of cannabis or cannabinoids have also been demonstrated in multiple sclerosis patients (Notcutt, 2015), and cannabinoids may be useful for the treatment of other auto-immune disorders such as rheumatoid arthritis, fibromyalgia, and Crohn's disease (Ware et al, 2010; Katchan et al, 2016; Katz et al, 2016). Although it is difficult to recruit a balanced sample of each sex for human trials of auto-immune disease, one wonders whether the beneficial effects that have been reported thus far are due to the prevalence of women participants in these studies. Other therapeutic indications that have been explored but do not include sex-dependent analyses include cannabinoid treatment of PTSD (Jetly et al, 2015), chemotherapy-induced nausea and vomiting (ie, Ungerleider et al, 1982), and AIDS- and HIV-induced cachexia (ie, Beal et al, 1997). Although sex-dependent therapeutic effects have not been assessed a priori, the following sections describe investigations that included exploratory assessments of drug effects as a function of sex, or that assessed sex differences in retrospective analyses of data pooled from several studies.

Analgesia. Although sex differences in cannabinoid-induced analgesia have not been assessed in a patient population, these differences have been explored in one study of healthy 
participants. The analgesic and antihyperalgesic effects of nabilone $(0.5$ and $1.0 \mathrm{mg}$ ) were compared to placebo using a model of noxious, long-lasting heat stimulation in noncannabis-using, healthy participants. In this study, nabilone did not reduce pain intensity relative to placebo. However, the high dose decreased hyperalgesia in women but not men (Table 1; Redmond et al, 2008). Based on these findings, the authors suggest that cannabinoids may be helpful for women suffering from chronic pain.

A recent analysis sought to determine if cannabis-using men and women differed in cannabis-induced analgesia. In this double-blind, placebo-controlled study, healthy, and daily cannabis smokers were recruited, and the effects of smoked cannabis with THC (active cannabis) vs placebo cannabis (cannabis with no THC) were determined using the Cold Pressor Test, a laboratory pain assay that has predictive validity for clinically effective analgesics used for chronic pain. Men and women did not differ in subjective ratings of analgesia such as bothersomeness of the painful stimulus. However, for objective measures of pain, cannabis elicited greater analgesia compared to placebo-cannabis in men relative to women: men exhibited a robust analgesic response as measured by latency to feel pain, whereas women did not. Active cannabis also increased participants' ability to tolerate the painful stimulus to a greater extent in men than in women. Despite the differences in cannabis-induced analgesia, men and women showed comparable subjective effects related to abuse liability (Table 1; Cooper and Haney, 2016). These findings demonstrated that among daily cannabis smokers, women do not appear to be sensitive to the analgesic effects of cannabis, while adverse effects associated with abuse liability are retained. These results were limited by the inclusion of a single strength of active cannabis (3.56$5.6 \% \mathrm{THC}$ ), the smoked route of administration, which is not the preferred route for the therapeutic use of cannabinoids, and the study population consisting of normal healthy controls rather than a patient population.

Chemotherapy-induced nausea. A significant proportion of randomized, placebo-controlled studies of the therapeutic utility of cannabinoids has investigated their effectiveness for chemotherapy-induced nausea and vomiting, and HIV- and cancer-related cachexia (Whiting et al, 2015), yet few studies have analyzed sex-dependent differences in these clinical End points. One study explored possible sex differences in the effectiveness of cannabinoids to stimulate appetite in patients with cancer-related anorexia-cachexia syndrome. Patients were randomized to receive oral THC $(2.5 \mathrm{mg})$, a cannabis extract that contained cannabidiol $(1 \mathrm{mg})$ and THC $(2.5 \mathrm{mg})$, or placebo twice a day for 6 weeks. Self-reported measures of appetite, mood, nausea, and quality of life were compared between men and women as a function of medication condition. Women exhibited greater improvements in appetite under the medication conditions (oral THC alone and the cannabis extract that included THC and cannabidiol), yet no sex differences were observed for other End points, including ratings of nausea or quality of life measures (Strasser et al, 2006).

Adverse effects. As mentioned previously, adverse events associated with cannabis use in clinical trials are rarely serious, and are predominately reports of dizziness followed by gastrointestinal complaints including nausea and vomiting (Wang et al, 2008). There is little evidence that the type and frequency of adverse events in response to cannabinoid administration differs between men and women; however, a single laboratory study suggests that women may be more sensitive than men to cannabinoid-induced dizziness (Mathew et al, 2003). There have also been recent reports of intense bouts of vomiting and gastrointestinal distress in chronic cannabis smokers, called cannabinoid hyperemesis syndrome (CHS); whether these cases are recreational or medical cannabis users is not clear. A recent analysis synthesizing findings from case reports found that men were overwhelmingly more likely to be diagnosed with CHS relative to women (72.9 vs 27.1\%; Sorenson et al, 2016). However, this sex discrepancy may reflect heavier cannabis use reported among men relative to women (ie, Cuttler et al, 2016) rather than a sex-specific sensitivity to this adverse effect of cannabis.

In summary, survey data suggest that women and men utilize medical cannabis at similar rates, although there is evidence that the symptoms for which they use medical cannabis differ, as do their methods of use (Cuttler et al, 2016). Recent efforts have sought to elucidate differences in efficacy of FDA-approved therapeutics between men and women to better help guide treatment decisions. However, few studies have explored whether sex-dependent therapeutic effects of cannabinoids exist. Data from surveys, laboratorybased studies, and one study in a clinical population suggest that men and women may differ in their responses to cannabinoids, yet the direction of this sex difference may depend on the End points used and the population studied (patients, non-cannabis-using healthy controls, or cannabisusing healthy controls). Important pharmacological variables that are likely to influence sex-dependent effects are the drug tested (ie, nabilone, dronabinol, cannabis, or cannabidiol), route of administration (ie, smoked, oral, or vaporized), dose administered, and duration of treatment. More comprehensive sex comparisons of the therapeutic effects of cannabis and cannabinoids in human populations are needed.

\section{CANNABINOID ABUSE LIABILITY AND DEPENDENCE}

\section{Preclinical Evidence for Sex-Dependent Effects}

Preclinical models/markers of drug abuse. Several animal studies suggest that females may be more sensitive than males to the reinforcing and discriminative effects of cannabinoids. First, female rats of two strains acquired stable drug self-administration faster, self-administered more of the synthetic cannabinoid agonist WIN55,212-2 during 
the maintenance phase, took longer to extinguish responding when vehicle was substituted for WIN55,212-2, and showed greater drug- and cue-primed reinstatement than males (Fattore et al, 2007, 2010). Female rats also learned to discriminate THC from vehicle at a lower dose than males ( 1 vs $3 \mathrm{mg} / \mathrm{kg}$ ), and acquired the discrimination significantly faster (Wiley et al, 2017). THC discrimination was also acquired in $\sim 30 \%$ fewer sessions in female compared to male mice (Wiley et al, 2011). The only study comparing cannabinoid place preference/aversion between the sexes reported no significant THC effect in either sex (Hempel et al, 2017), although the highest dose tested, $6 \mathrm{mg} / \mathrm{kg}$, reduced time spent on the THC-paired side by $~ 30 \%$ in male but not female rats. Thus, the limited number of animal studies published to date suggests that female rodents are more sensitive than males to the reinforcing and discriminative stimulus effects of cannabinoids.

Sex-dependent tolerance and dependence. Several studies have examined sex differences in the development of tolerance to THC in adult female rats compared to males. In two studies comparing tolerance development to the 'tetrad' of cannabinoid effects (antinociception, locomotor suppression, catalepsy, and hypothermia) in male $v s$ female, adolescent $v s$ adult rats (Wiley et al, 2007; Wiley and Burston, 2014) or in adolescents bred in-house vs shipped (Wiley and Evans, 2009), robust tolerance developed to all four 'tetrad' effects and no sex differences in tolerance development were observed. However, the high-dose $(10 \mathrm{mg} /$ $\mathrm{kg}), 10$-day chronic THC regimen led to nearly complete flattening of most dose-effect curves in all groups, so the magnitude of tolerance development was difficult to distinguish among groups. Tolerance to THC's cataleptic effect did appear to be greater in adolescent females than males in one of these studies, although group sample sizes were relatively small and the sex difference was not statistically significant (Wiley and Burston, 2014). In a subsequent study using doses of THC lower than $10 \mathrm{mg} / \mathrm{kg}$ to induce tolerance, female rats developed significantly more antinociceptive tolerance than males, measured as a greater decrease in THC potency in females than males (Wakley et al, 2014). Similar sex differences were reported in a later tolerance study from the same lab, using the same acute pain tests (Wakley et al, 2015). Notably, in the latter two studies the tolerance-inducing dose of THC was sex-specific ( $\sim 30-40 \%$ lower in females than males) to adjust for greater THC potency in females before tolerance induction. Thus, even when treated with lower doses than males, females developed greater tolerance than males. In contrast, another study in adult rats showed that when $10 \mathrm{mg} / \mathrm{kg}$ THC was administered daily, more rapid tolerance occurred in males compared to females responding on a repeated acquisition and performance operant task (Weed et al, 2016). Finally, another study in which a low dose of THC $(2 \mathrm{mg} / \mathrm{kg})$ was given chronically to juvenile (PND22-40) or late adolescent rats (PND41-60), no tolerance development was observed in either sex (Harte and Dow-Edwards, 2010). In the only study examining the effects of chronic THC in male $v s$ female mice, several days of THC treatment resulted in significantly altered locomotor activity only in females: tolerance developed to the stimulant effects of a low THC dose $(1 \mathrm{mg} / \mathrm{kg})$ and sensitization developed to the stimulant effects of a high dose $(30 \mathrm{mg} / \mathrm{kg}$; Wiley, 2003). In summary, the few studies that have examined sex differences in the development of tolerance to cannabinoids suggest that females develop tolerance more readily than males to the antinociceptive effects of THC, but there are very few studies of tolerance development to cannabinoid effects other than antinociception. Additionally, cannabinoid tolerance is known to be dose-dependent and to develop at different rates for different effects (Gonzalez et al, 2005), so in the future it will be important to conduct sex comparisons of cannabinoid tolerance to a variety of effects using a variety of dose ranges and dosing frequencies.

In regard to cannabinoid dependence, several studies report sex differences in animals. In one study, a high dose of THC $(30 \mathrm{mg} / \mathrm{kg})$ was administered twice-daily for 6.5 days to adult female and male rats, and then withdrawal was precipitated with the $\mathrm{CB} 1$ antagonist rimonabant $(10 \mathrm{mg} / \mathrm{kg})$. The only significant sex difference among the many withdrawal symptoms assessed was that females showed more retropulsion (walking backwards) than males did (Marusich et al, 2014). A second study conducted in adult rats also used rimonabant $(1.0 \mathrm{mg} / \mathrm{kg})$-precipitated withdrawal: after 40 days of $10 \mathrm{mg} / \mathrm{kg} /$ day THC treatment, females showed more disrupted performance (increased errors, decreased response rate) than males in the performance component of a repeated acquisition, 3-response sequence task (Weed et al, 2016). A third study examined spontaneous withdrawal symptoms after termination of chronic THC treatment of adolescent rats. Rats were given either $2,7.5$, or $15 \mathrm{mg} / \mathrm{kg}$ daily from PND35-41, and then tested on the elevated plusmaze on PND 42, 44, and 56. Early in withdrawal, males that had been treated with the higher doses of THC showed evidence of decreased anxiety whereas females showed evidence of increased anxiety (Harte-Hargrove and DowEdwards, 2012). Overall, limited evidence suggests that female rats may develop greater tolerance and greater cannabinoid dependence than males, although results may be end point-specific, and may also depend on the dose and duration of the chronic cannabinoid treatment.

\section{Clinical Evidence for Sex-Dependent Effects}

Epidemiology studies have consistently demonstrated that men have a higher rate of problematic cannabis use marked by increased chronicity of use (Preston, 2006), longer episodes of CUD, and greater cannabis use as measured by number of cannabis cigarettes smoked per day (Khan et al, 2013). Additionally, prevalence rates of CUD are higher among males relative to females during adolescence (Hayatbakhsh et al, 2009, and see Farmer et al, 2015: lifetime prevalence rates of DSM-IV cannabis abuse or dependence from 16 to 30 years of age was $22.5 \%$ of the male 
population $v s \quad 16.4 \%$ of the female population), and in adulthood (Haberstick et al, 2014: lifetime prevalence of DSM-IV cannabis dependence diagnosis in men was 10.9 vs $6.1 \%$ in women). The increase in risk observed among men relative to women may not be due to biological underpinnings, but rather due to social factors that limit exposure to cannabis and decrease the likelihood of cannabis initiation and use in females, including greater perception of risk, decreased cannabis use among peers, and greater childcare responsibilities. However, epidemiological studies are showing that sex differences in cannabis use are shrinking, suggesting that societal constraints on cannabis use among females are abating. An analysis of data from the National Youth Risk Behavior Survey, a large, biennial, school-based survey, demonstrated that while boys consistently show higher prevalence rates than girls for lifetime and current cannabis use, the gap decreased over a 14-year period between 1999 and 2013, with a difference of 7.6 percentage points between boys and girls in 1999 for prevalence of lifetime cannabis use $v s$ a difference of 2.9 percentage points in 2013 (Johnson et al, 2015); this shrinking gender gap has also been observed at the national level among adolescent and adult respondents (Substance Abuse and Mental Health Services Administration, 2014a,b,). Furthermore, findings from the annual National Survey on Drug Use and Health (NSDUH) from 2002 through 2014 show that past-month cannabis use increased among pregnant women from $2.37 \%$ to $3.85 \%$. Among non-pregnant women, past month use increased by close to $4 \%$ in women $18-25$ years of age, and close to $3 \%$ in women overall (18-44 years of age; Brown et al, 2017). Given the narrowing gap in cannabis use among adolescent and adult males $v s$ females, identifying sexdependent effects of cannabis associated with the development of CUD and probing the biological basis for these differences is a public health imperative.

Abuse-related subjective effects. Sex differences in response to the acute effects associated with abuse liability of cannabis and cannabinoids have been examined using double-blind, placebo-controlled laboratory procedures. End points that have been assessed include subjective drug ratings related to positive drug effects and cue-induced craving. Similar to studies investigating sex differences in the therapeutic effects of cannabinoids, sex differences related to abuse liability were mostly analyzed as an exploratory aim or by pooling data from several studies in order to obtain sufficient statistical power to detect a significant difference between men and women. A recent laboratory study compared the discriminative stimulus and subjective effects of oral THC in male and female non-treatment-seeking cannabis users. While men and women did not appear to be differentially sensitive to the discriminative stimulus effects of oral THC, a dose-dependent sex difference emerged with respect to THC's subjective effects that are indicative of abuse liability. Women exhibited greater sensitivity to the lowest THC dose tested $(5 \mathrm{mg})$ and reported higher ratings related to abuse liability, including ratings of drug liking, desire to take the dose again, and good drug effect. In contrast, men reported higher subjective ratings of drug liking than women for the higher THC dose $(15 \mathrm{mg})$. The sample used for this study consisted of men and women who did not differ in cannabis use, with average use reported to be 4.5 days per week and about 3 cannabis cigarettes/day (Fogel et al, 2017). An earlier study investigating the effects of higher oral THC doses (20 and $40 \mathrm{mg}$ ) in male and female cannabis smokers failed to find sex-dependent effects with regard to subjective ratings. However, differences emerged when assessing these effects in non-cannabis users: men were more sensitive than women to the intoxicating effects (ie, ratings of 'High') of oral THC (2.5-10 mg) (Haney, 2007).

Studies with smoked cannabis reveal mixed effects. One study that investigated the subjective ratings of smoked cannabis included participants whose smoking frequency ranged from once per month to three times per week. Women were reported to have a slower latency to detect cannabis's psychoactive effects and a shorter duration of its effects compared to men, suggesting that men were more sensitive to cannabis's subjective effects (Penetar et al, 2005). This study did not specify if men and women differed in current cannabis use. Given the wide range of cannabis use frequency among participants in this study (one time per month to three times a week), differences in current cannabis use between men and women may have influenced the findings. A second study assessing sex-dependent subjective effects of smoked cannabis matched men and women according to current cannabis use (Cooper and Haney, 2014). Among daily cannabis smokers, females were more sensitive than males to subjective effects related to abuse liability, including ratings of drug liking and willingness to take the drug again. However, males and females did not differ in ratings of intoxication ('High'). These findings indicate that under double-blind, placebo-controlled procedures, female daily cannabis smokers are more sensitive than their male counterparts to the subjective experience that is associated with cannabis abuse liability. Although subjective effects provide a measure of abuse potential, drug selfadministration is the best measure of abuse liability because it best reflects drug-taking in the natural ecology. To date, no studies have assessed possible differences in cannabis or cannabinoid self-administration between men and women.

Together, these findings suggest that sex differences in THC-induced subjective effects depend on dose, route of administration (oral vs smoked), and population (cannabis users $v s$ non-users). These findings are directly relevant to the population using cannabis for medical indications, which varies in previous and current exposure to cannabis and cannabis-derived products. In addition, these findings highlight the differences across studies that can emerge as a function of route of administration, a variable that should be addressed in future studies, particularly given the increasing popularity of edibles (Cuttler et al, 2016).

Cue-induced craving. Cannabis craving as a measure of addiction severity has been studied as a function of participant sex. Men and women who smoked similar amounts of 
cannabis were presented with tactile, visual, and olfactory cannabis-related cues and were asked to rate their craving for, urge, and desire to smoke cannabis. No sex differences were detected in baseline craving. While craving for, urge, and desire to smoke cannabis increased in response to the cues, differences between men and women were not detected (Lundahl and Johanson, 2011). A second study probed the potential utility of oral THC (10 and $20 \mathrm{mg}$ ) for treating CUD in daily cannabis smoking men and women by determining its effects on cannabis cue-elicited craving (Lundahl and Greenwald, 2015). In this study, cannabis cues increased ratings associated with compulsivity, or inability to control cannabis use, anxiety, and urge to smoke cannabis relative to a neutral cue. Oral THC decreased cueelicited craving and anxiety, an effect that did not differ between men and women. However, sex-dependent effects were observed for ratings of compulsivity, with women exhibiting significant decreases on this measure after receiving either dose of oral THC, whereas oral THC failed to attenuate this rating in men (Lundahl and Greenwald, 2015). These data suggest that THC differentially attenuates aspects of subjective responses related to continued cannabis use between men and women, and have implications for the use of THC as a potential pharmacotherapy for CUD.

Withdrawal. Although women and men report similar patterns of cannabis use, women seeking treatment for problematic use score higher on a measure of severity of drug dependence (Copeland et al, 2001). One indication of severity of drug dependence is the presence and severity of withdrawal symptoms after cessation of cannabis use. Earlier studies examining withdrawal symptoms among nontreatment-seeking male and female cannabis users found that men and women reported different symptoms: women reported nausea, whereas men endorsed goose-bumps and cannabis craving (Agrawal et al, 2008; Copersino et al, 2010). A later survey similarly assessed sex differences in selfreported withdrawal symptoms and also found that more women reported nausea and anxiety, whereas men more frequently reported sleep disruptions (Cuttler et al, 2016). A recent study sought to study incidence and severity of withdrawal symptoms as a function of sex during a cannabis quit attempt in a population of treatment-seeking cannabis users (Herrmann et al, 2015). This study carefully controlled for cannabis dependence inclusion criteria, excluded other drug dependencies (eg, alcohol) and characterized participants based on amount of cannabis use in the previous 90 days, ensuring that men and women were matched for current cannabis use. Women reported more withdrawal symptoms relative to men and had significantly higher scores on symptoms related to mood (including increased restlessness, irritability) and gastrointestinal symptoms (nausea and stomach pain). Women also reported greater symptom severity related to mood symptoms. A later study of treatment-seeking cannabis users similarly found that women endorsed more withdrawal symptoms and negative impact of withdrawal symptoms relative to men who were matched for past-month cannabis use; sex differences in the severity of specific symptoms were found for hot flashes, headache, mood swings, irritability, gastrointestinal symptoms, and sleep disturbances (Sherman et al, 2017). While men and women had similar patterns of cannabis use, women were more likely to have psychiatric diagnoses and reported lower quality of life compared to men, which may have contributed to differences in self-reported incidence and severity of withdrawal symptoms.

Clinical trials for CUD. Clinical trials investigating potential pharmacotherapies to treat CUD do not typically assess outcomes according to sex (recent studies include Allsop et al, 2014; Levin et al, 2016). However, recent studies investigated the potential for sex-dependent treatment effects with the selective serotonin receptor inhibitor and partial 5-HT1A agonists, vilazodone and buspirone, for cannabis dependence (McRae-Clark et al, 2015, 2016). While these pharmacotherapies were not effective in reducing cannabis use relative to placebo for either sex, the authors found that women had worse outcomes relative to men in relation to cannabis craving and in difficulty achieving abstinence. These findings agree with earlier reports demonstrating that women report greater withdrawal symptom severity relative to men.

Given that severity of withdrawal is hypothesized to contribute to ongoing use and relapse to use in a treatment setting (Budney et al, 2008; Haney et al, 2013), these studies suggest that women may experience greater difficulty than men achieving and maintaining abstinence from cannabis use. Understanding how men and women differ in regard to incidence and severity of withdrawal symptoms during abstinence can help to guide research into sex-specific pharmacotherapies for cannabis dependence, increasing treatment success for both men and women. A limitation of these studies is that assessments were based on retrospective self-report measures, requiring participants to recall from memory the incidence and severity of their withdrawal symptoms. In addition, it is not clear whether cannabis exposure immediately prior to the quit attempt was comparable among men and women. Future studies should examine withdrawal symptoms according to both self-report and clinician-based assessments in real time, optimally after participants have been exposed to a known quantity and strength of cannabis. Accurate assessment of pharmacotherapies to target sex-specific withdrawal symptoms can be best examined under these circumstances.

Other End points related to cannabis addiction severity. Differences among men and women in neural correlates associated with severity of cannabis addiction were recently explored in a positron emission tomography (PET) study that measured brain glucose metabolism utilizing the radiotracer $\left[{ }^{18} \mathrm{~F}\right]$ deoxyglucose. Differences in brain glucose metabolism were compared in healthy, non-cannabis-using controls relative to daily cannabis users who met DSM-IV criteria for cannabis abuse or dependence in response to placebo administration and a methylphenidate challenge 
(Wiers et al, 2016). Under placebo conditions, cannabis users exhibited lower glucose metabolism relative to healthy controls in the frontal cortex and anterior cingulate. In response to the methylphenidate challenge, cannabis users exhibited blunted regional metabolism compared to healthy controls; moreover, regional increases in glucose metabolism in response to methylphenidate were negatively correlated with addiction severity. In regard to sex differences, the differences between healthy controls and cannabis users in both placebo and methylphenidate-induced changes in metabolism were driven by the female cannabis users. That is, female cannabis users exhibited lower glucose metabolism after placebo administration relative to female healthy controls, an effect that was not observed when comparing cannabis-using men to non-cannabis-using men. Furthermore, increases in methylphenidate-induced glucose metabolism were apparent in the female healthy controls but not in the female cannabis users. The authors conclude that women who use cannabis may be more susceptible than men to the adverse neurobiological effects of cannabis, including negative emotionality and severity of addiction (Wiers et al, 2016).

The above findings demonstrate that men and women differ in End points associated with cannabis's abuse liability, withdrawal from cannabis, and neurobiological End points associated with cannabis addiction severity. These effects were assessed in response to smoked cannabis and oral THC in populations of non-cannabis users, light users, and heavy users. Multiple studies report that cannabis-dependent women experience more difficulty than cannabisdependent men with withdrawal symptoms, a finding that is consistent with results showing enhanced negative effects of cannabis in women who are daily smokers, including increases in subjective effects that reflect abuse liability, and deficits in neurobiological markers associated with addiction severity. Given the differences observed across studies as a function of cannabis exposure, these findings highlight the need to match women and men according to current cannabis use in order to control for the potential effects of tolerance that may alter adverse effects of cannabis, withdrawal, cue-induced craving, and investigation of neural markers of addiction severity. A significant gap in our knowledge regarding differences between men and women in relation to CUD is self-administration during nonabstinent and abstinent conditions, and a systematic assessment of withdrawal symptoms as a function of sex while controlling for cannabis exposure preceding cessation of use, as well as withdrawal assessments that include clinician-based ratings and objective measures.

\section{MECHANISMS UNDERLYING SEX-DEPENDENT EFFECTS OF CANNABINOIDS}

\section{Gonadal Hormones}

Sexual differentiation of cannabinoid sensitivity could arise from the direct influence of sex chromosomes (eg, genes on the $\mathrm{X} v s \mathrm{Y}$ chromosomes that control cannabinoid receptor expression), or indirectly from organizational (early developmental) or activational (pubertal to adult) effects of gonadal hormones on the endocannabinoid system (Becker et al, 2005). Direct sex chromosome influence has not yet been investigated for any cannabinoid effect. Sex differences in behavioral effects of cannabinoids have been observed on some End points in adolescent rats (PND40: Romero et al, 2002; PND41: Harte and Dow-Edwards, 2010) and even in pre-pubertal rats (PND28-29: Llorente-Berzal et al, 2011; but see Borcel et al, 2004 and Wiley et al, 2007), suggesting that sex differences begin to develop early in life. No studies have been conducted to determine whether neonatal gonadectomy, a method typically undertaken to examine organizational effects of gonadal hormones, abolishes sex differences in behavioral effects of cannabinoids. Studies of activational hormone effects (eg, gonadectomy with or without hormone replacement in adulthood) suggest that testosterone can dampen gonadectomized male and female rats' sensitivity to the motor-impairing effects of systemic THC, while enhancing females' but not males' sensitivity to THC's antinociceptive effect against acute pain; conversely, estradiol can enhance female and male rats' sensitivity to THC's antinociceptive effect without significantly altering their sensitivity to THC's motor-impairing effects, although the estradiol effect is not consistent across all studies (Craft and Leitl, 2008; Wakley et al, 2014, 2015; Craft et al, 2017). Progesterone alone has been reported to decrease systemic THC's antinociceptive potency (Wakley et al, 2015), but it did not significantly affect i.c.v. THC-induced antinociception (Wakley et al, 2014) in female rats ovariectomized as adults. In gonadally intact female rats, acute antinociceptive sensitivity to THC also has been shown to fluctuate across the estrous cycle, with peak sensitivity to THC at the time of ovulation or shortly thereafter (Craft and Leitl, 2008; Wakley et al, 2011). Endocannabinoids such as anandamide and 2arachidonyl glycerol (2-AG) have also been shown to fluctuate across the rat estrous cycle in some brain areas, with the greatest changes around the time of ovulation or shortly thereafter (Bradshaw et al, 2006). In contrast to results obtained with systemically administered THC and tests of acute pain, using a model of masseter muscle inflammatory pain, Niu et al (2012) showed that adult male rats' antinociceptive sensitivity to a peripherally (i.m.) administered CB1 receptor-selective agonist was decreased by castration, and this appeared to be due to a testosteronedependent decrease in trigeminal ganglia CB1 receptor density. In contrast to studies of acute cannabinoid antinociception, gonadectomy and hormone replacement did not significantly alter the development of tolerance to THC-induced antinociception (Wakley et al, 2015), although flattening of the post-chronic THC dose-effect curves in this study limited the precision of tolerance quantification. In a study of cannabinoid dependence (rimonabant-precipitated withdrawal) in gonadectomized and hormone-replaced adult male and female rats, it was concluded that estradiol and progesterone tended to promote dependence in females 
while testosterone tended to blunt dependence in males, although hormone effects tended to be subtle and inconsistent across End points (Marusich et al, 2015).

Several other behavioral effects of cannabinoids have been shown to be modulated by gonadal hormones in adulthood. For example, adult ovariectomy decreased female rats' selfadministration of WIN55,212-2 (Fattore et al, 2007), and self-administration was restored to that of gonadally intact females by estradiol replacement (Fattore et al, 2010). In several other studies female rats were ovariectomized peripubertally (PND30) and then studied as adults; in these cases, early ovariectomy decreased females' later sensitivity to THC's disruptive effects on a repeated acquisition operant task (Winsauer et al, 2011; Winsauer and Sutton, 2014), and decreased the slope of a THC discrimination curve (ie, THC's efficacy appeared to be lower in ovariectomized females compared to gonadally intact females: Winsauer et $a l, 2012)$. It is not yet known whether modulation of THC's cognitive effects by ovariectomy is due to estradiol, progesterone, or both. In addition to these presumably genomic (slower) effects of gonadal hormones, rapid membrane estrogen receptor (ER)-mediated effects on the cannabinoid system have been documented. For example, WIN55,212-2-induced hyperphagia in ovariectomized guinea pigs is attenuated by estradiol acting at both nuclear ERalpha and membrane ER in hypothalamic neurons (Washburn et al, 2013). In summary, there is growing evidence that sexual differentiation of cannabinoid drug sensitivity is due at least in part to activational effects of gonadal steroid hormones. Given that peri-pubertal ovariectomy of female rats can also modulate cannabinoid sensitivity (Winsauer et al, 2011; Winsauer et al, 2012; Winsauer and Sutton, 2014), and administration of the same hormone to adult male and female gonadectomized rats does not change cannabinoid sensitivity in the same way (Craft et al, 2017), it is likely that organizational gonadal hormone milieu and possibly sex chromosomes also contribute to sexual differentiation of cannabinoid sensitivity.

In humans, there is also evidence that gonadal hormones influence the cannabinoid system. For example, endocannabinoid tone has been shown to vary across the menstrual cycle. Peak plasma anandamide levels are observed during ovulation and are positively associated with estradiol, luteinizing hormone, and follicle stimulating hormone suggesting that these hormones may play a role in regulating anandamide levels (El-Talatini et al, 2010). Interestingly, low levels of anandamide and high levels of fatty acid amide hydrolase, the enzyme that degrades anandamide, are detected after ovulation during the luteal phase in the peripheral lymphocytes of normally cycling, non-cannabis smoking females (Lassarin et al, 2004). Given the evidence in the preclinical literature that changes in endocannabinoid tone across the female's cycle are also mediated by changes in cannabinoid receptor density, affinity and function (eg, Rodriguez de Fonseca et al, 1994), menstrual phase-related changes in endocannabinoid tone should influence the behavioral effects of cannabis and cannabinoids. However, very few studies address this issue in the human literature assessing therapeutic or abuse-related effects of cannabinoids. Most studies examining effects of cannabinoids in women either did not control for menstrual cycle phase or only assessed effects during the mid-follicular phase when circulating reproductive hormones (progesterone, estradiol, FSH, and LH) are low (Normandin et al, 2015; Weirs et al, 2016). An early study investigated the effect of menstrual cycle phase on self-reported measures of mood, behavioral changes, and cannabis smoking in daily female cannabis smokers using daily diary entries; phase was estimated based on daily diary reports that tracked the onset of menses. No changes in cannabis use were detected as a function of menstrual cycle phase (follicular, periovulatory, luteal, premenstrual, and menstrual phases) over three cycles (Griffin et al, 1986).

\section{Pharmacokinetics}

In rats, sex differences in the metabolism of THC contribute to sex differences observed in behavioral effects of THC. After acute THC injection, females produce more of the major active metabolite 11-OH-THC than males do (Tseng et al, 2004; Wiley and Burston, 2014; Britch et al, 2017). This sex difference in 11-OH-THC production is modulated by gonadal hormones (Craft et al, 2017), observed in adolescent as well as adult rats, and increases in magnitude with repeated THC treatment (Wiley and Burston, 2014). Greater production of 11-OH-THC by females appears to be due to different cytochrome P450 enzymes produced by the female $v s$ male rat liver, such that females metabolize THC primarily to 11-OH-THC and the major inactive metabolite THC$\mathrm{COOH}$, whereas males produce less $11-\mathrm{OH}-\mathrm{THC}$ but a wider array of (mostly inactive) metabolites (Narimatsu et al, 1991, 1992). Blocking the hydroxylation of THC to 11-OH-THC by pre-treating rats with a non-selective cytochrome $\mathrm{P} 450$ inhibitor decreases THC-induced antinociception and catalepsy in female but not male rats, essentially eliminating the sex difference in these THC effects (Tseng and Craft, 2004). Sex differences in liver enzymes involved in THC metabolism have also been documented in mice (Watanabe et al, 1992). In humans, an early study reported no significant sex differences in THC metabolism after oral or intravenous (i.v.) THC administration (Wall et al, 1983). However, a later study with oral THC (that had double the sample size of the earlier study) demonstrated significantly greater $C_{\max }$, shorter $t_{\max }$, and greater AUC in women than in men, particularly for 11-OH-THC (Nadulski et al, 2005). Although THC dosing was not adjusted by body weight in this study, correction for sex differences in body weight did not eliminate the sex difference in metabolic indices, and blood levels of cannabinoids were also not correlated with BMI (Nadulski et al, 2005). No studies to date have investigated differences between men and women in THC pharmacokinetics after smoked cannabis administration. Thus, it would appear that sex differences in THC metabolism occur across species, although the differences may be 
larger in rats than in humans. It is not known to what extent sex differences in metabolism underlie sex differences in behavioral effects of cannabinoids besides THC. In addition, sex differences in THC's effects have been observed when THC is administered i.c.v. (Wakley et al, 2011) and locally into the rat hindpaw (Craft et al, 2013), routes that preclude hepatic THC metabolism, suggesting that sex differences in cannabinoid pharmacodynamics must also be important contributors to sex differences in behavioral effects of cannabinoids.

\section{Pharmacodynamics}

Preclinical studies demonstrate that the antinociceptive effects of THC and CP55,940 are CB1 and/or CB2 receptormediated in rats of both sexes (Craft et al, 2012, 2013). Systemically administered rimonabant, a CB1 receptorselective antagonist, was significantly more potent in females than males in blocking the acute antinociceptive effects of systemic THC and CP55,940 (Craft et al, 2012), suggesting that rimonabant has greater affinity for the $\mathrm{CB} 1$ receptor in females than males. However, when given supraspinally or spinally, rimonabant was more similar in its potency in male and female rats to block the acute antinociceptive effects of systemic THC (Tseng and Craft, 2004), suggesting that the greater potency of systemically administered rimonabant in females compared to males may reflect a pharmacokinetic sex difference. THC's peripheral antinociceptive effect (intraplantar injection of antagonist plus THC) was similarly antagonized in both sexes by a low dose of rimonabant; however, THC's local antinociceptive effect was also blocked by a low dose of the CB2 receptor-selective antagonist SR144528 in females but not males (Craft et al, 2013). Two other studies report limited antagonism of THC's behavioral effects by SR144528 in females but not males (Craft et al, 2012; Wiley et al, 2017), suggesting that females may have more CB2 receptors than males do, or that THC has greater affinity for or efficacy at $\mathrm{CB} 2$ receptors in females than males.

In rats, sex differences in $\mathrm{CB} 1$ receptor mRNA or receptor protein density or binding affinity have been reported in prefrontal cortex (male > female: Castelli et al, 2014), amygdala (male > female: Castelli et al, 2014; female > male: Riebe et al, 2010), cerebellum (female >male: Xing et al, 2011), hippocampus (male > female: Reich et al, 2009; Weed et al, 2016), hypothalamus (male $>$ female: Reibe et al, 2010), brainstem (female $>$ male: Xing et al, 2011), mesencephalon (male > female: Rodriguez de Fonseca et al, 1994), and anterior pituitary (male > female: Gonzalez et al, 2000). However, sex differences are not entirely consistent across studies for the same brain area, and some studies report no sex differences in some of these same brain areas (eg, Rodriguez de Fonseca et al, 1994; Riebe et al, 2010; Casteels et al, 2014; Castelli et al, 2014), suggesting that methodological details such as how rats are handled (ie, stress), what estrous stage females are in, and various biochemical parameters of the mRNA or protein assay may be crucial.
Only one study in CB1 receptor knockout animals has been conducted. Male but not female $\mathrm{CB} 1$ receptor knockout mice showed greater anxiety-like behavior than wild-type controls, despite the fact that rimonabant increased anxiety-like behavior in knockouts of both sexes (Bowers and Ressler, 2016), further suggesting that CB1 receptors may function differently in the two sexes. Finally, a comprehensive study of sex differences in brain endocannabinoid content in the rat revealed sex differences in multiple brain areas. For example, females had greater 2-AG levels than males in hypothalamus and pituitary, and lower 2-AG levels in cerebellum, and estrous cycle-dependent sex differences were additionally found in hippocampus (anandamide) and midbrain (2-AG and anandamide; Bradshaw et al, 2006).

In addition to studies demonstrating sex differences in CB1 receptor number or affinity, some studies report sex differences in $\mathrm{CB} 1$ receptor-mediated signal transduction (typically assessed via GTPyS assay) in addition to, or in the absence of sex differences in CB1 receptor density or affinity (eg, Castelli et al, 2014), and it has been suggested that sex differences in cannabinoid receptor density $v s$ affinity $v s$ signal transduction may functionally compensate for each other (for review, see Rubino and Parolaro, 2011).

Beyond sex differences in cannabinoid receptor pharmacology, there is growing preclinical evidence that gonadal hormones, particularly estradiol, may influence cannabinoid receptor density or function. Estrous cycle and/or ovariectomy plus hormone replacement have been reported to modulate CB1 receptor density or affinity (Rodriguez de Fonseca et al, 1994; Riebe et al, 2010; Castelli et al, 2014; Wakley et al, 2014) as well as endocannabinoid content (Bradshaw et al, 2006) in various brain areas. Furthermore, estradiol-induced decreases in CB1 receptor signaling observed in the cortex and hippocampus of ovariectomized female rats were observed when estradiol was given acutely but not when it was given chronically (Mize and Alper, 2000), a potentially important finding given that many behavioral studies of estradiol effect involve chronic estradiol treatment. Testosterone has also been shown to modulate CB1 receptor density in brain (Rodriguez de Fonseca et al, 1994) and in trigeminal ganglia (Niu et al, 2012; Lee et al, 2013a) of male rats.

Various studies have also documented sex differences in, or gonadal hormone modulation of, the effects of stress or chronic THC exposure (in adolescence or adulthood) on brain cannabinoid receptor pharmacology. For example, chronic THC exposure during adolescence or adulthood decreased $\mathrm{CB} 1$ receptor density similarly in all groups of rats, but $\mathrm{CB} 1$ receptor desensitization was greater in adolescent females than males in multiple brain areas (Burston et al, 2010). Chronic adolescent THC exposure also increased CB1 receptor mRNA and decreased GTPYS signaling in the amygdala of female but not male rats (Silva et al, 2016; but see Mateos et al, 2011), increased hippocampal $\mathrm{CB} 1$ receptor density in adult female rats but decreased it in males (Weed et al, 2016), and decreased 
CREB phosphorylation in the prefrontal cortex and hippocampus (and increased CREB phosphorylation in nucleus accumbens) of adult female but not male rats (Rubino et al, 2008). Chronic stress has also been reported to decrease hippocampal CB1 receptor density in male rats while increasing it in females (Reich et al, 2009). In summary, although there are some inconsistencies across studies, sex differences in cannabinoid receptor pharmacology have been demonstrated under conditions of no cannabinoid exposure, and acute and chronic cannabinoid exposure, suggesting that sex differences in behavioral effects of cannabinoids are due at least in part to sex differences in cannabinoid receptor pharmacology.

Several clinical studies have compared cannabinoid receptor pharmacology between men and women. Onaivi et al (1999) reported greater cannabinoid receptor density in healthy, non-cannabis using women compared to men, using blood samples of leukocytes (cells known to be involved in inflammatory pain responses), an intriguing finding that remains to be confirmed. PET studies with the radiotracer $\left[{ }^{11} \mathrm{C}\right]$ OMAR developed for imaging of the CB1 receptor recently reported findings suggesting that among healthy, non-cannabis using participants who were 18-65 years of age, women $(N=5)$ tested during their follicular phase had higher CB1 availability relative to men $(N=5$; Normandin et al, 2015). This effect was also observed in a study investigating $\left[{ }^{11} \mathrm{C}\right] \mathrm{OMAR}$ volume of distribution in both non-cannabis using healthy controls and participants diagnosed with PTSD. Female participants exhibited greater CB1 receptor availability relative to men in both the healthy control and PTSD groups (Neumeister et al, 2013). These findings are in contrast to studies using a different CB1 receptor radiotracer, $\left[{ }^{18} \mathrm{~F}\right] \mathrm{MK}-9470$ in healthy non-cannabis using participants, which suggest greater density in men than in women, for example in the cortico-striato-thalamic circuit (Van Laere et al, 2008). Interestingly, in this study, density increased with age among women specifically in the limbic system, basal ganglia, and lateral temporal cortex, an effect that was not observed in men. While recent PET studies with $\left[{ }^{11} \mathrm{C}\right] \mathrm{OMAR}$ suggest that cannabis use is associated with CB1 receptor downregulation in men (D'Souza et al, 2016), to date, no studies have assessed CB1 receptor radiotracer binding in cannabis users as a function of sex. The greater CB1 receptor availability in women observed in some of these studies suggests that relative to men, women may be more sensitive to both the therapeutic and adverse effects of CB1 receptor agonists, like THC in cannabis.

\section{SYNTHESIS OF FINDINGS FROM PRECLINICAL AND CLINICAL STUDIES}

Although cannabis is the most frequently used illicit drug (Center for Behavioral Health Statistics and Quality, 2016), scientific investigations exploring how men and women may differ in response to its effects are just beginning. Few clinical studies have investigated sex differences in the acute and long-term effects of cannabis and cannabinoids in regard to therapeutic and abuse-related effects. Data that do exist are largely from observational and retrospective approaches rather than a priori investigation, which can have a significant impact on the quality of the findings, as it is difficult to control for variables including drug history, current drug use, and demographics that may influence sexdependent effects in these types of study designs. For studies on the therapeutic effects of cannabis and cannabinoids, differences in severity of disease state and concomitant medications between men and women are factors that should be taken into account. Furthermore, studies investigating these effects (1) across a range of routes of administration (ie, smoked, vaporized, and oral), and (2) in non-cannabis using populations are important in guiding our understanding and in generalizability of the therapeutic utility of cannabis and cannabinoids. Ensuring that men and women are matched according to severity of dependence and frequency of current cannabis use is critical for cannabis abuse liability and dependence studies. Despite the paucity of data from clinical studies, growing evidence from preclinical a priori investigations into sex-dependent effects of cannabinoids have provided a foundation from which predictions can be made regarding sex-dependent effects in humans. Findings from preclinical studies provide insight into variables that significantly influence sex differences, such as age of first exposure, end point of interest, hormonal status (ie, estrous cycle phase), and degree of exposure (dose, frequency and duration of exposure).

While some of the evidence from clinical studies regarding differences between men and women does not directly correspond to preclinical findings, commonalities arise that strongly support the value of translational investigations of these effects. In agreement with preclinical studies demonstrating that females are more sensitive than males to the antinociceptive effects of acute cannabinoid administration, healthy, non-cannabis using women, but not men, were shown to be sensitive to the anti-hyperalgesic effect of nabilone (Redmond et al, 2008). In contrast, a laboratorybased study with healthy, daily cannabis users found that men were more sensitive to the cannabis-elicited analgesia relative to women (Cooper and Haney, 2016), findings that may be considered to align with preclinical data demonstrating greater development of tolerance to cannabinoid-induced antinociception in females than males (Wakley et al, 2014, 2015). That is, after repeated exposure to THC, THC may be a more potent antinociceptive agent in male compared to female rats. Results from clinical studies examining sex differences of the negative effects of cannabis related to its abuse liability are also mixed, although the aggregate data suggest that withdrawal severity is greater in women relative to men (Agrawal et al, 2008; Copersino et al, 2010; Herrmann et al, 2015; Sherman et al, 2017). These observations agree with preclinical findings that female rats show greater withdrawal effects under spontaneous and precipitated withdrawal, such as more disruption in 
performance on cognitive tasks (Weed et al, 2016), more anxiety-like behavior (Harte-Hargrove and Dow-Edwards, 2012), and more retropulsion (Marusich et al, 2014) relative to males. These findings have significant implications for taking sex into consideration when addressing treatment for CUD.

Divergent findings between laboratory animal and human studies may be due to multiple methodological differences. For instance, the route of cannabis and cannabinoid administration in human studies is restricted to smoking, vapor inhalation, or oral, whereas animal studies primarily employ local, i.c.v., i.v., or i.p. cannabinoid administration. Another significant discrepancy between rodent and human studies is the degree of control that animal studies afford regarding history and current cannabinoid exposure. Although matching men and women according to current and history of cannabis use can be achieved with regard to smoking frequency and amount smoked per day, the amount of THC and other cannabinoids in cannabis can vary considerably between participants. As such, total THC exposure can differ regardless of matching for frequency of use. Animal studies regarding sex-dependent tolerance to $\mathrm{CB} 1$ receptor agonists suggest that adjusting chronic THC exposure as a function of initial THC sensitivity between males and females may be important to 'equalize exposure' between the sexes (Wakley et al, 2014, 2015), but this cannot be done in human studies of established cannabis users. One way to circumvent this issue when assessing cannabis- and cannabinoid-induced effects is to test the end point in question only after exposing the study population to known quantities of cannabis of a particular strength (ie, THC concentration) for some period of time. This strategy would limit differences in current cannabis exposure that may impact sex-dependent effects and is a strategy that has been implemented to assess cannabis withdrawal in the laboratory (ie, Haney et al, 2013). Another important difference between animal and human studies is the ability to control for the effects of fluctuating reproductive hormones. There is significant evidence from animal studies demonstrating that reproductive hormones can modify the effects of cannabinoids (ie, Craft and Leitl, 2008; Fattore et al, 2010; Wakley and Craft, 2011; Castelli et al, 2014; Marusich et al, 2015; Wakley et al, 2015). While sex-dependent effects have emerged in several human studies that have not controlled for menstrual cycle phase, evaluating effects according to phase would help to elucidate how reproductive hormones contribute to differences between men and women. However, it should be noted that the largest changes in the brain endocannabinoid system and in sensitivity to exogenous cannabinoids in rats appear to occur around the time of ovulation. Given that the ovulatory period in women is quite short relative to other cycle phases (Reed and Carr, 2015), the impact of menstrual cycle over a long period of cannabis or cannabinoid use may not be particularly important. Studying cannabinoids in animal models that incorporate variables that impact cannabinoid effects in the clinic, such as route of administration and duration of exposure, would likely improve translation from the bench to the clinic.

\section{IMPLICATIONS OF FINDINGS}

Sex differences in any phenomenon can be categorized as quantitative - phenomena that are essentially the same but differ in magnitude between the sexes, or qualitative phenomena that occur only in one sex, or that differ in underlying mechanism (Mogil and Bailey, 2010). At this point primarily quantitative sex differences in cannabinoid effects have been demonstrated in animal and, to a lesser degree, in human studies. That is, cannabinoid drugs have been found to be more or less potent, and in a few cases more or less efficacious, in one sex compared to the other, on a variety of End points. Small sex differences in therapeutic drug potency are unlikely to be important clinically, because drug dose can be readily adjusted up or down to compensate for any individual difference in drug effect. In contrast, large sex differences in therapeutic drug potency, or sex differences in therapeutic drug efficacy are more likely to be clinically significant, since escalating drug dose to compensate for relative lack of effect results in no gain in effect (when efficacy is low), and/or overwhelming adverse effects. Increasing dose to compensate for a lack of potency or efficacy can also lead to greater development of tolerance and dependence. These consequences of increasing drug dose have significant implications when considering the potential utility of cannabis and cannabinoids as a viable therapeutic option. Considering that cannabis is widely used recreationally, sex differences in initial potency and efficacy may also affect the likelihood of developing CUD, and achieving and maintaining abstinence in people who seek treatment for this disorder. Findings from preclinical studies demonstrate that females are particularly sensitive to the reinforcing effects of a CB1 receptor agonist (Fattore et al, 2007, 2010). These findings coupled with epidemiological and smaller observational studies reporting that women accelerate to problematic cannabis use at a faster rate than males and exhibit more severe withdrawal symptoms when abstinent underscore the importance of addressing sex-dependent effects of cannabis and cannabinoids for both therapeutic and abuseliability perspectives.

\section{LIMITATIONS AND FUTURE RESEARCH DIRECTIONS}

In addition to the suggestions noted above regarding clinical studies, we note several caveats to the published preclinical and clinical research on sex differences in cannabinoid effects, as well as some potential future directions. First, developmental factors in preclinical studies such as prepubertal or adolescent cannabinoid or other drug exposure, and environmental factors such as diet, and whether rats are bred in-house $v s$ shipped have been shown to modulate cannabinoid effects in adult rats, in some cases in a sex- 
specific manner (Marco et al, 2006; Wiley and Evans, 2009; Wiley et al, 2011; Silva et al, 2016). Given the important role of the endocannabinoid system in brain development and response to stress (Dow-Edwards and Silva, 2017), this is not surprising, and it likely contributes to discrepancies in results across studies. Researchers are encouraged to be aware of methodological variables that have been shown to have sex-specific impact on outcomes of interest, and to choose methods accordingly. Second, some published sex difference studies may be under-powered. For example, very similar effect sizes using larger $v s$ smaller samples can be found in studies that report statistically significant $v s$ non-significant sex differences, respectively, in THC-induced antinociception (eg, Craft et al, 2012 vs Wiley et al, 2007), and discrimination (Wiley et al, 2017 vs Wiley et al, 2011). Thus, researchers are encouraged to power studies appropriately to test for sex differences, rather than add more confusion to the literature by concluding that there are no sex differences based on inadequately sized samples. For clinical studies, investigating sex-dependent effects should be prioritized when designing a study, to increase the quality of findings and to control for variables that limit interpretations of observational and retrospective studies. Third, more animal research needs to be done using models of cannabinoid selfadministration to examine male $v s$ female propensity to 'selfmedicate' under conditions of stress/anxiety, chronic pain, etc. Control over (or prediction of) drug administration has been shown to produce different effects for a variety of drugs (see Donny et al, 2006), and addressing discrepancies between human and animal studies in this regard may help to optimize translation of results from animals to humans. Fourth, animal studies of sex differences in cannabinoid effects have focused on adolescents to young adults, and even human studies tend not to include older participants (ie, above 55 years of age), but there may be age-related differences in cannabinoid effects. The growing demographic of older cannabis users (Hasin et al, 2015; Han et al, 2017) highlights the importance of assessing age in future sex differences research. Fifth, although there are animal studies examining sex differences in behavior after chronic cannabinoid administration, with the exception of studies by the Winsauer lab $(2011 ; 2012 ; 2014 ; 2016)$, the longest periods of administration tend to be 10 days; in contrast, many human studies of cannabinoid effect are conducted in chronic cannabis users who have been using for years. To the extent that there may be sex differences in the development of tolerance to and dependence on cannabinoids, continuing to examine only acute effects of cannabinoids in animals will provide only limited information relevant to human use. For clinical studies, it is also important to assess the safety, tolerability, and efficacy of cannabis and cannabinoids in non-cannabis users as a function of sex, as patients who turn to medical cannabis and cannabinoids are not necessarily current cannabis users. Sixth, the major non-psychoactive component of cannabis, cannabidiol (CBD), is emerging as a cannabis constituent with potentially diverse therapeutic effects, but there are almost no sex comparisons of its effects, even in animals. Given the emerging evidence that TRPV1 channels-a major CBD target-are estradiol-modulated (Yamagata et al, 2016), examining sex differences in a variety of CBD effects is warranted.

Finally, it should be noted that to date, only a few laboratories have examined sex differences in either therapeutic or abuse-related effects of cannabinoids in either animals or humans, so it remains to be seen whether sex differences observed in the early studies reviewed herein will be replicated by other laboratories using more strains and species as well as a wider spectrum of End points. In addition, very few animal (or human) sex difference studies have obtained complete doseand time-effect curves for the cannabinoid effects of interest. These parameters are crucial for determining whether observed sex differences reflect sex differences in drug potency, drug efficacy, onset and/or duration of action. It can be argued that the most clinically important sex differences in drug effect would be sex differences in drug efficacy, since a lesser maximal effect in one sex compared to the other has many implications for treatment as well as abuse liability (see implications). Thus, it will be important in future studies to comprehensively characterize sex differences in all pharmacological parameters of cannabinoid effect.

\section{FUNDING AND DISCLOSURE}

Dr Cooper's research is funded by the National Institute on Drug Abuse, Grant DA039123 and DA036809. She has received partial salary support for investigator-initiated studies from Insys Therapeutics Inc. Dr Craft's research is funded by NIDA DA016644, and by funds provided for medical and biological research by the State of Washington (Initiative Measure 171). The authors declare no conflict of interest.

\section{REFERENCES}

Abrams DI, Jay CA, Shade SB, Vizoso H, Reda H, Press S et al (2007). Cannabis in painful HIV-associated sensory neuropathy: a randomized placebo-controlled trial. Neurology 68: 515-521.

Aggarwal SK, Carter GT, Sullivan MD, ZumBrunnen C, Morrill R, Mayer JD (2009). Characteristics of patients with chronic pain accessing treatment with medical cannabis in Washington State. J Opioid Manag 5: 257-286.

Agrawal A, Pergadia ML, Lynskey MT (2008). Is there evidence for symptoms of cannabis withdrawal in the national epidemiologic survey of alcohol and related conditions? Am J Addict 17: 199-208.

Allsop DJ, Copeland J, Lintzeris N, Dunlop AJ, Montebello M, Sadler C et al (2014). Nabiximols as an agonist replacement therapy during cannabis withdrawal: a randomized clinical trial. JAMA Psychiatry 71: 281-291.

Beal JE, Olson R, Laubenstein L, Morales JO, Bellman P, Yangco B et al (1997). Dronabinol as a treatment for anorexia associated with weight loss in patients with AIDS. J Pain Symptom Manage 10: 89-97.

Becker JB, Arnold AP, Berkley KJ, Blaustein JD, Eckel LA, Hampson E et al (2005). Strategies and methods for research on sex differences in brain and behavior. Endocrinology 146: 1650-1673 A comprehensive, practical guide for conducting sex differences research in pharmacology and neuroscience.

Bonn-Miller MO, Boden MT, Bucossi MM, Babson KA (2014). Self-reported cannabis use characteristics, patterns and helpfulness among medical cannabis users. Am J Drug Alcohol Abuse 40: 23-30.

Borcel E, Perez-Alvarez L, de Ceballos ML, Ramirez BG, Marco EM, Fernandez B et al (2004). Functional responses to the cannabinoid agonist WIN 55,212-2 in neonatal rats of both genders: influence of weaning. Pharmacol Biochem Behav 78: 593-602. 
Bowers ME, Ressler KJ (2016). Sex-dependence of anxiety-like behavior in cannabinoid receptor 1 (Cnr1) knockout mice. Behav Brain Res 300: 65-69.

Bradshaw HB, Rimmerman N, Krey JF, Walker JM (2006). Sex and hormonal cycle differences in rat brain levels of pain-related cannabimimetic lipid mediators. Am J Physiol Regul Integr Comp Physiol 291: R349-R358.

Britch SC, Wiley JL, Yu Z, Clowers BH, Craft RM (2017). Cannabidiol-delta-9tetrahydrocannbinol interactions on acute pain and locomotor activity. Drug Alcohol Depend 175: 187-197.

Brown QL, Sarvet AL, Shmulewitz D, Martins SS, Wall MM, Hasin DS (2017). Trends in marijuana use among pregnant and nonpregnant reproductive-aged women, 2002-2014. JAMA 317: 207-209.

Brownjohn PW, Ashton JC (2012). Spinal cannabinoid CB2 receptors as a target for neuropathic pain: an investigation using chronic constriction injury. Neuroscience 203: 180-193.

Budney AJ, Vandrey RG, Hughes JR, Thostenson JD, Bursac Z (2008). Comparison of cannabis and tobacco withdrawal: severity and contribution to relapse. J Subst Abuse Treat 35: 362-368.

Buggy DJ, Toogood L, Maric S, Sharpe P, Lambert DG, Rowbotham DJ (2003). Lack of analgesic efficacy of oral delta-9-tetrahydrocannabinol in postoperative pain. Pain 106: 169-172.

Burston JJ, Wiley JL, Craig AA, Selley DE, Sim-Selley LJ (2010). Regional enhancement of cannabinoid CB1 receptor desensitization in female adolescent rats following repeated $\Delta^{9}$-tetrahydrocannabinol exposure. $\mathrm{Br} J$ Pharmacol 161 : 103-112.

Casteels C, Gerard N, van Kuyck K, Pottel L, Nuttin B, Bormans G et al (2014). Small animal PET imaging of the type 1 cannabinoid receptor in a rodent model for anorexia nervosa. Eur J Nucl Med Mol Imaging 41: 308-321.

Castelli MP, Fadda P, Casu A, Spano MS, Casti A, Fratta W et al (2014). Male and female rats differ in brain cannabinoid CB1 receptor density and function and in behavioural traits predisposing to drug addiction: effect of ovarian hormones. Curr Pharm Des 20: 2100-2113.

Center for Behavioral Health Statistics and Quality (2016). Key substance use and mental health indicators in the United States: Results from the 2015 National Survey on Drug Use and Health (HHS Publication No. SMA 16-4984, NSDUH Series H-51) https://www.samhsa.gov/data/sites/default/files/NSDUH-FFR1-2015/ NSDUH-FFR1-2015/NSDUH-FFR1-2015.htm (accessed on 21 February 2017).

Compton WM, Han B, Hughes A, Jones CM, Blanco C (2017). Use of marijuana for medical purposes among adults in the United States. JAMA 317: 209-211.

Cooper ZD, Haney M (2014). Investigation of sex-dependent effects of marijuana in daily marijuana smokers. Drug Alcohol Depend 136: 85-91.

Cooper ZD, Haney M (2016). Sex-dependent effects of cannabis-induced analgesia. Drug Alcohol Depend 167: 112-120 An analysis of the analgesic and subjectiveeffects related to abuse liability of smoked cannabis in men and women matched for current cannabis use.

Copeland J, Swift W, Rees V (2001). Clinical profile of participants in a brief intervention program for cannabis use disorder. $J$ Subst Abuse Treat 20: 45-52.

Copersino ML, Boyd SJ, Tashkin DP, Huestis MA, Heishman SJ, Dermand JC et al (2010). Sociodemographic characteristics of cannabis smokers and the experience of cannabis withdrawal. Am J Drug Alcohol Abuse 36: 311-319.

Craft R, Leitl M (2008). Gonadal hormone modulation of the behavioral effects of Delta(9)-tetrahydrocannabinol in male and female rats. Eur J Pharmacol 578: $37-42$.

Craft RM, Haas AE, Wiley JL, Yu Z, Clowers BH (2017). Gonadal hormone modulation of $\Delta^{9}$-tetrahydrocannabinol-induced antinociception and metabolism in female versus male rats. Pharmacol Biochem Behav 152: 36-43.

Craft RM, Kandasamy R, Davis SM (2013). Sex differences in anti-allodynic, antihyperalgesic and anti-edema effects of $\Delta(9)$-tetrahydrocannabinol in the rat. Pain 154: 1709-1717 Demonstrates greater antinociception in female rats, but greater reductions in paw edema in males after both systemic and local THC administration.

Craft RM, Marusich JA, Wiley JL (2013). Sex differences in cannabinoid pharmacology: a reflection of differences in the endocannabinoid system? Life Sci 92: 476-481.

Craft RM, Wakley AA, Tsutsui KT, Laggart JD (2012). Sex differences in CB1 vs. CB2 receptor-selective antagonism of antinociception produced by delta-9-THC and CP55,490 in the rat. J Pharmacol Exp Ther 340: 787-800.

Cui JH, Woon MK, Lee HG, Kim YO, Kim CM, Yoon MH (2011). Antinociceptive effect of intrathecal cannabinoid receptor agonist WIN 55,212-2 in a rat bone tumor pain model. Neurosci Lett 493: 67-71.

Cuttler C, Mischley LK, Sexton M (2016). Sex differences in cannabis use and effects: a cross-sectional survey of cannabis users. Cannabis Cannabinoid Res $\mathbf{1}$ : 167-175.

Donny EC, Bigelow GE, Walsh SL (2006). Comparing the physiological and subjective effects of self-administered vs yoked cocaine in humans. Psychopharmacology 186: 544-552.
Dow-Edwards D, Silva L (2017). Endocannabinoids in brain plasticity: cortical maturation, HPA axis function and behavior. Brain Res 1654: 157-164.

D'Souza DC, Cortes-Briones JA, Ranganathan M, Thurnauer H, Creatura G, Surti T et al (2016). Rapid changes in CB1 receptor availability in cannabis dependent males after abstinence from cannabis. Biol Psychiatry Cogn Neurosci Neuroimaging 1: 60-67.

Ehlers CL, Gizer IR, Vieten C, Gilder DA, Stouffer GM, Lau P et al (2010). Cannabis dependence in the San Francisco Family Study: age of onset of use, DSM-IV symptoms, withdrawal, and heritability. Addict Behav 35: 102-110.

Ellis RJ, Toperoff W, Vaida F, van den Brande G, Gonzales J, Gouaux B et al (2009). Smoked medicinal cannabis for neuropathic pain in HIV: a randomized, crossover clinical trial. Neuropsychopharmacology 34: 672-680.

El-Talatini MR, Taylor AH, Konje JC (2010). The relationship between plasma levels of the endocannabinoid, anandamide, sex steroids, and gonadotrophins during the menstrual cycle. Fertil Steril 93: 1989-1996.

Farmer RF, Kosty DB, Seeley JR, Duncan SC, Lynskey MT, Rohde P et al (2015). Natural course of cannabis use disorders. Psychol Med 45: 63-72.

Fattore L, Spano MS, Altea S, Angius F, Fadda P, Fratta W (2007). Cannabinoid selfadministration in rats: sex differences and the influence of ovarian function. Brit $J$ Pharmacol In combination with the 2010 paper from the same lab, a convincing demonstration that females of $\mathrm{LE}$ and $\mathrm{LH}$ strains are more sensitive than males to the reinforcing effects of WIN55,212-2-but note that neither females nor males of the SD strain acquired self-administration 152: 795-804.

Fattore L, Spano MS, Altea S, Fadda P, Fratta W (2010). Drug- and cue-induced reinstatement of cannabinoid-seeking behaviour in male and female rats: influence of ovarian hormones. Brit J Pharmacol 160: 724-735.

Fogel JS, Kelly TH, Westgate PM, Lile JA (2017). Sex differences in the subjective effects of oral $\triangle$ 9-THC in cannabis users. Pharmacol Biochem Behav 152: 44-51.

Finseth TA, Hedeman JL, Brown RP 2nd, Johnson KI, Binder MS, Kluger BM (2015). Self-reported efficacy of cannabis and other complementary medicine modalities by Parkinson's disease patients in Colorado. Evid Based Complement Alternat Med 2015: 874849.

Gonzalez S, Cebeira M, Fernandez-Ruiz J (2005). Cannabinoid tolerance and dependence: a review of studies in laboratory animals. Pharmacol Biochem Behav 81: 300-318.

Gonzalez S, Bisogno T, Wenger T, Manzanares J, Milone A, Berrendero F et al (2000). Sex steroid influence on cannabinoid CB1 receptor mRNA and endocannabinoid levels in the anterior pituitary gland. Biochem Biophys Res Commun 270: 260-266.

Greenwald MK, Stitzer ML (2000). Antinociceptive, subjective and behavioral effects of smoked marijuana in humans. Drug Alcohol Depend 59: 261-275.

Griffin ML, Mendelson JH, Mello NK, Lex BW (1986). Marihuana use across the menstrual cycle. Drug Alcohol Depend 18: 213-224.

Gu XP, Mei FM, Liu Y, Zhang R, Zhang J, Ma ZL (2011). Intrathecal administration of the cannabinoid 2 receptor agonist JWHO15 can attenuate cancer pain and decrease mRNA expression of the 2B subunit of N-Methyl-D-Aspartic acid. Anesth Analg 113: 405-411.

Gui H, Tong Q, Qu W, Mao C-M, Dai S-M (2015). The endocannabinoid system and its therapeutic implications in rheumatoid arthritis. Int Immunopharmacol 26: 86-91.

Haberstick BC, Young SE, Zeiger JS, Lessem JM, Hewitt JK, Hopfer CJ (2014). Prevalence and correlates of alcohol and cannabis use disorders in the United States: results from the national longitudinal study of adolescent health. Drug Alcohol Depend 136: 158-161.

Han BH, Sherman S, Mauro PM, Martins SS, Rotenberg J, Palamar JJ (2017). Demographic trends among older cannabis users in the United States, 2006-13. Addiction 112: 516-525.

Haney M (2007). Opioid antagonism of cannabinoid effects: differences between marijuana smokers and nonmarijuana smokers. Neuropsychopharmacology 32: 1391-1403 Reports on differences in subjective responses to oral THC as a function of cannabis use and sex.

Haney M, Bedi G, Cooper ZD, Glass A, Vosburg SK, Comer SD et al (2013). Predictors of marijuana relapse in the human laboratory: robust impact of tobacco cigarette smoking status. Biol Psychiatry 73: 242-248.

Harte LC, Dow-Edwards D (2010). Sexually dimorphic alterations in locomotion and reversal learning after adolescent tetrahydrocannabinol exposure in the rat. Neurotoxicol Teratol 32: 515-524.

Harte-Hargrove LC, Dow-Edwards DL (2012). Withdrawal from THC during adolescence: sex differences in locomotor activity and anxiety. Behav Brain Res 231: 48-59.

Hasin DS, Saha TD, Kerridge BT, Goldstein RB, Chou SP, Zhang $\mathrm{H}$ et al (2015). Prevalence of marijuana use disorders in the United States between 2001-2002 and 2012-2013. JAMA Psychiatry 72: 1235-1242 This study reports on findings from population-based data on trends in cannabis use and CUD over 10-year period when the number of states legalizing cannabis for medical use increased. 
Hayatbakhsh MR, Najman JM, Bor W, O'Callaghan MJ, Williams GM (2009). Multiple risk factor model predicting cannabis use and use disorders: a longitudinal study. Am J Drug Alcohol Abuse 35: 399-407.

Hempel BJ, Wakeford AGP, Nelson KH, Clasen MM, Woloshchuk CJ, Riley AL (2017). An assessment of sex differences in $\Delta 9$-tetrahydrocannabinol (THC) taste and place conditioning. Pharmacol Biochem Behav 153: 69-75.

Herrmann ES, Weerts EM, Vandrey R (2015). Sex differences in cannabis withdrawal symptoms among treatment-seeking cannabis users. Exp Clin Psychopharmacol 23: 415-421 Differences in cannabis withdrawal symptom type and severity between men and women are presented.

Hernandez-Avila CA, Rounsaville BJ, Kranzler HR (2004). Opioid-, cannabis-and alcohol-dependent women show more rapid progression to substance abuse treatment. Drug Alcohol Depend 74: 265-272.

Hilarius DL, Kloeg PH, van der Wall E, van den Heuvel JJG, Gundy CM, Aaronson NK (2012). Chemotherapy-induced nausea and vomiting in daily clinical practice: a community hospital-based study. Support Care Cancer 20: 107-117.

Issa MA, Narang S, Jamison RN, Michna E, Edwards RR, Penetar DM et al (2014). The subjective psychoactive effects of oral dronabinol studied in a randomized, controlled crossover clinical trial for pain. Clin J Pain 30: 472-478.

Jetly R, Heber A, Fraser G, Boisvert D (2015). The efficacy of nabilone, a synthetic cannabinoid, in the treatment of PTSD-associated nightmares: a preliminary randomized, double-blind, placebo-controlled cross-over design study. Psychoneuroendocrinology 51: 585-588.

Johnson RM, Fairman B, Gilreath T, Xuan Z, Rothman EF, Parnham T et al (2015). Past 15-year trends in adolescent marijuana use: differences by race/ethnicity and sex. Drug Alcohol Depend 155: 8-15.

Karst M, Salim K, Burstein S, Conrad I, Hog C, Schneider U (2003). Analgesic effect of the synthetic cannabinoid CT-3 on chronic neuropathic pain. JAMA 290: 1757-1762.

Katchan V, David P, Shoenfeld Y (2016). Cannabinoids and autoimmune diseases: a systematic review. Autoimmun Rev 15: 513-528.

Katz D, Katz I, Porat-Katz BS, Shoenfeld Y (2016). Medical cannabis: another piece in the mosaic of autoimmunity? Clin Pharm Ther 101: 230-238.

Ketcherside A, Baine J, Filbey F (2016). Sex effects of marijuana on brain structure and function. Curr Addict Rep 3: 323-331.

Khan SS, Secades-Villa R, Okuda M, Wang S, Pérez-Fuentes G, Kerridge BT et al (2013). Gender differences in cannabis use disorders: results from the National Epidemiologic Survey of Alcohol and Related Conditions. Drug Alcohol Depend 130: 101-108

Klein SL, Flanagan KL (2016). Sex differences in immune responses. Nat Rev Immunol 16: 626-638.

Kraft B, Frickey NA, Kaufmann RM, Reif M, Frey R, Gustorff B et al (2008). Lack of analgesia by oral standardized cannabis extract on acute inflammatory pain and hyperalgesia in volunteers. Anesthesiology 109: s101-s110.

Lazzarin N, Valensise H, Bari M, Ubaldi F, Battista N, Finazzi-Agrò A et al (2004). Fluctuations of fatty acid amide hydrolase and anandamide levels during the human ovulatory cycle. Gynecol Endocrinol 18: 212-218.

Lee KS, Asgar J, Zhang Y, Chung M-K, Ro JY (2013a). The role of androgen receptor in transcriptional modulation of cannabinoid receptor type 1 gene in rat trigeminal ganglia. Neuroscience 254: 395-403.

Lee MC, Ploner M, Wiech K, Bingel U, Wanigasekera V, Brooks J et al (2013b). Amygdala activity contributes to the dissociative effect of cannabis on pain perception. Pain 154: 124-134

Levin FR, Mariani JJ, Pavlicova M, Brooks D, Glass A, Mahony A et al (2016). Dronabinol and lofexidine for cannabis use disorder: A randomized, double-blind, placebo-controlled trial. Drug Alcohol Depend 159: 53-60.

Llorente-Berzal A, Fuentes S, Gagliano H, López-Gallardo M, Armario A, Viveros M-P et al (2011). Sex-dependent effects of maternal deprivation and adolescent cannabinoid treatment on adult rat behavior. Addict Biol 16: 524-637.

Lundahl LH, Johanson CE (2011). Cue-induced craving for marijuana in cannabisdependent adults. Exp Clin Psychopharmacol 19: 224-230.

Lundahl LH, Greenwald MK (2015). Effect of oral THC pretreatment on marijuana cue-induced responses in cannabis dependent volunteer. Drug Alcohol Depend 149: 187-193.

Lynch ME, Ware MA (2015). Cannabinoids for the treatment of chronic non-cancer pain: an updated systematic review of randomized controlled trials. $J$ Neuroimmune Pharmacol 10: 293-301.

Macúchová E, Ševčíková M, Hrebič́ková I, Nohejlová K, Šlamerová R (2016). How various drugs affect anxiety-related behavior in male and female rats prenatally exposed to methamphetamine. Int J Dev Neurosci 51: 1-11.

Malfait AM, Gallily R, Sumariwalla PF, Malik AS, Andreakos E, Mechoulam R et al (2000). The nonpsychoactive cannabis constituent cannabidiol is an oral antiarthritic therapeutic in murine collagen-induced arthritis. Proc Natl Acad Sci USA 97: 9561-9566.
Mareno-Martet M, Feliú A, Espejo-Porras F, Mecha M, Carrillo-Salinas FJ, Fernández-Ruiz J et al (2015). The disease-modifying effects of a Sativex-like combination of phytocannabinoids in mice with experimental autoimmune encephalomyelitis are preferentially due to $\Delta 9$-tetrahydrocannabinol acting through CB1 receptors. Mult Scler Relat Disord 4: 505-511.

Marco EM, Llorente R, Moreno E, Biscaia JM, Guaza C, Viveros MP (2006). Adolescent exposure to nicotine modifies acute functional responses to cannabinoid agonists in rats. Behav Brain Res 172: 46-53.

Marusich JA, Craft RM, Lefever TW, Wiley JL (2015). The impact of gonadal hormones on cannabinoid dependence. Exp Clin Psychopharmacol 23: 206-216.

Marusich JA, Lefever TW, Antonazzo KR, Craft RM, Wiley JL (2014). Evaluation of sex differences in cannabinoid dependence. Drug Alcohol Depend 137: 20-28.

Mateos B, Borcel E, Loriga R, Luesu W, Bini V, Llorente R et al (2011). Adolescent exposure to nicotine and/or the cannabinoid agonist CP 55,940 induces gender-dependent long-lasting memory impairments and changes in brain nicotinic and CB1 cannabinoid receptors. J Psychopharmacol 25 1676-1690.

Mathew RJ, Wilson WH, Davis R (2003). Postural syncope after marijuana: a transcranial Doppler study of the hemodynamics. Pharmacol Biochem Behav 75 309-318.

McConnell BV, Applegate M, Keniston A, Kluger B, Maa EH (2014). Use of complementary and alternative medicine in an urban county hospital epilepsy clinic. Epilepsy Behav 34: 73-76.

McRae-Clark AL, Baker NL, Gray KM, Killeen TK, Wagner AM, Brady KT et al (2015). Buspirone treatment of cannabis dependence: a randomized, placebocontrolled trial. Drug Alcohol Depend 156: 29-37.

McRae-Clark AL, Baker NL, Gray KM, Killeen T, Hartwell KJ et al (2016). Vilazodone for cannabis dependence: a randomized, controlled pilot trial. Am J Addict 25 : 69-75

Mize AL, Alper RH (2000). Acute and long-term effects of $17 \beta$-estradiol on $\mathrm{G}_{\mathrm{i} / \mathrm{o}}$ coupled neurotransmitter receptor function in the female rat brain as assessed by agonist-stimulated $\left[{ }^{35}\right.$ S $]$ GTP $\gamma S$ binding. Brain Res 859: 326-333.

Mogil JS, Bailey AL (2010). Sex and gender differences in pain and analgesia. Prog Brain Res 186: 141-157.

MPP (Marijuana Policy Project) (2016). State-by-State Medical Marijuana Laws https://www.mpp.org/issues/medical-marijuana/state-by-state-medical-marijua na-laws/state-by-state-medical-marijuana-laws-report/ (Accessed on 2 May 2017).

Nadulski T, Pragst F, Weinberg G, Roser P, Schnelle M, Fronk E-M et al (2005). Randomized, double-blind, placebo-controlled study about the effects of cannabidiol (CBD) on the pharmacokinetics of $\Delta^{9}$-tetrahydrocannabinol (THC) after oral application of THC versus standardized cannabis extract. Ther Drug Monit 27: 799-809.

Naef M, Curatolo M, Petersen-Felix S, Arendt-Nielsen L, Zbinden A, Brenneisen R (2003). The analgesic effect of oral delta-9-tetrahydrocannabinol (THC), morphine, and a THC-morphine combination in healthy subjects under experimental pain conditions. Pain 105: 79-88.

Narimatsu S, Watanabe K, Matsunaga T, Yamamoto I, Imaoka S, Funae $\mathrm{Y}$ et al (1992). Cytochrome P-450 isozymes involved in the oxidative metabolism of $\Delta^{9}$ tetrahydrocannabinol by liver microsomes of adult female rats. Drug Metab Dispos 20: 79-82.

Narimatsu S, Watanabe K, Yamamoto I, Yoshimura H (1991). Sex differences in the oxidative metabolism of $\Delta^{9}$-tetrahydrocannabinol in the rat. Biochem Pharmacol 41: 1187-1194.

National Academies of Sciences, Engineering, and Medicine. The Health Effects of Cannabis and Cannabinoids: The Current State of Evidence and Recommendation for Research. The National Academies Press: Washington, DC, 2017.

NCSL (National Conference of State Legislatures) (2017). State medical marijuana laws. February 17, 2017 http://www.ncsl.org/research/health/state-medicalmarijuana-laws.aspx (accessed on 19 February 2017).

Neumeister A, Normandin MD, Pietrzak RH, Piomelli D, Zheng MQ, Gujarro-Anton A et al (2013). Elevated brain cannabinoid CB1 receptor availability in post-traumatic stress disorder: a positron emission tomography study. $\mathrm{Mol}$ Psychiatry 18: 1034-1040 An investigation of differences in circulating endocannabinoids and markers of CB1 receptor availability as a function of sex and PTSD diagnosis.

Niu KY, Zhang Y, Ro JY (2012). Effects of gonadal hormones on the peripheral cannabinoid receptor 1 (CB1R) system under a myositis condition in rats. Pain 153: 2283-2291 In combination with the Lee et al (2013a) study from the same lab, this study provides a systematic exploration of how gonadal steroids, the immune system and the endocannabinoid system interact to affect pain.

Notcutt WG (2015). Clinical use of cannabinoids for symptom control in multiple sclerosis. Neurotherapeutics 12: 769-777. 
Normandin MD, Zheng M-Q, Lin K-S, Mason NS, Lin S-F, Ropchan J et al (2015). Imaging the cannabinoid CB1 receptor in humans with [11C]OMAR: assessment of kinetic analysis methods, test-retest reproducibility, and gender differences. J Cereb Blood Flow Metab 35: 1313-1322 An in-depth analysis and discussion of variables that can affect the interpretation of PET imaging data.

Noyes RJ, Brunk S, Baram DA, Canter A (1975). Analgesic effect of delta-9tetrahydrocannabinol. J Clin Pharmacol 15: 139-143.

Onaivi ES, Chaudhuri G, Abaci AS, Parker M, Manier DH, Martin PR et al (1999). Expression of cannabinoid receptors and their gene transcripts in human blood cells. Prog Neuropsychopharmacol Biol Psychiatry 23: 1063-1077.

Penetar DM, Kouri EM, Gross MM, McCarthy EM, Rhee CK, Peters EN et al (2005). Transdermal nicotine alters some of marihuana's effects in male and female volunteers. Drug Alcohol Depend 79: 211-223.

Pertwee RG (2008). Ligands that target cannabinoid receptors in the brain: from THC to anandamide and beyond. Addict Biol 13: 147-159.

Pini LA, Guerzoni S, Cainazzo MM, Ferrari A, Sarchielli P, Tiraferri I et al (2012). Nabilone for the treatment of medication overuse headache: results of a preliminary double-blind, active-controlled, randomized trial. J Headache Pain 13: 677-684.

Preston P (2006). Marijuana use as a coping response to psychological strain: racial, ethnic, and gender differences among young adults. Deviant Behav 27: 397-421.

Redmond WJ, Goffaux P, Potvin S, Marchand S (2008). Analgesic and antihyperalgesic effects of nabilone on experimental heat pain. Curr Med Res Opin 24: 1017-1024

Reed BG, Carr BR (2015). The normal menstrual cycle and the control of ovulation. In: De Groot LJ, Chrousos G, Dungan K et al eds Endotext [Internet]. MDText. com, Inc.: South Dartsmouth 9MA), 2000. https://www.ncbi.nlm.nih.gov/books/ NBK279054/.

Reich CG, Taylor ME, McCarthy MM (2009). Differential effects of chronic unpredictable stress on hippocampal CB1 receptors in male and female rats. Behav Brain Res 203: 264-269.

Riebe CJN, Hill MN, Lee TTY, Hillard CJ, Gorzalka BB (2010). Estrogenic regulation of limbic cannabinoid receptor binding. Psychoneuroendocrinology 35: 1265-1269.

Rock EM, Parker LA (2016). Cannabinoids as potential treatment for chemotherapyinduced nausea and vomiting. Front Pharmacol 7: 1-10.

Rodriguez de Fonseca F, Cebeira M, Ramos JA, Martín M, Fernández-Ruiz JJ (1994). Cannabinoid receptors in rat brain areas: sexual differences, fluctuations during estrous cycle and changes after gonadectomy and sex steroid replacement. Life Sci 54: 159-170.

Rog DJ, Nurmikko TJ, Young CA (2007). Oromucosal delta9-tetrahydrocannabinol/ cannabidiol for neuropathic pain associated with multiple sclerosis: an uncontrolled, open-label, 2-year extension trial. Clin Ther 29: 2068-2079.

Romero E, Fernández B, Sagredo O, Gomez N, Urigüen L, Guaza C et al (2002). Antinociceptive, behavioural and neuroendocrine effects of CP 55,940 in young rats. Brain Res Dev Brain Res 136: 85-92.

Rubino T, Sala M, Vigano D, Braida D, Castiglioni C, Limonta V et al (2007). Cellular mechanisms underlying the anxiolytic effect of low doses of peripheral $\Delta^{9}$-tetrahydrocannabinol in rats. Neuropsychopharmacology 32: 2036-2045.

Rubino T, Vigano D, Realini N, Guidali C, Braida D, Capurro V et al (2008). Chronic $\Delta^{9}$-tetrahydrocannabinol during adolescence provokes sex-dependent changes in the emotional profile in adult rats: behavioral and biochemical correlates. Neuropsychopharmacology 23: 2760-2771.

Rubino T, Parolaro D (2011). Sexually dimorphic effects of cannabinoid compounds on emotion and cognition. Front Behav Neurosci 5: 1-5.

Ryan-Ibarra S, Induni M, Ewing D (2015). Prevalence of medical marijuana use in California, 2012. Drug Alcohol Rev 34: 141-146.

Schepis TS, Desai RA, Cavallo DA, Smith AE, McFetridge A, Liss TB et al (2011). Gender differences in adolescent marijuana use and associated psychosocial characteristics. J Addict Med 5: 65-73.

Sherman BJ, McRae-Clark AL, Baker NL, Sonne SC, Killeen TK, Cloud K et al (2017). Gender differences among treatment-seeking adults with cannabis use disorder: clinical profiles of women and men enrolled in the achieving cannabis cessation-evaluating $\mathrm{N}$-acetylcysteine treatment (ACCENT) study. Am J Addict 26: $136-144$

Silva L, Black R, Michaelides M, Hurd YL, Dow-Edwards D (2016). Sex and age specific effects of delta-9-tetrahydrocannabinol during the periadolescent period in the rat: the unique susceptibility of the prepubescent animal. Neurotoxicol Teratol 58: 88-100.

Simone JJ, Green MR, Hodges TE, McCormick CM (2015). Differential effects of CB1 receptor agonism in behavioural tests of unconditioned and conditioned fear in adult male rats. Behav Brain Res 279: 9-16.
Sorensen CJ, DeSanto K, Borgelt L, Phillips KT, Monte AA (2016). Cannabinoid Hyperemesis syndrome: diagnosis, pathophysiology, and treatment-a systematic review. J Med Toxicol 13: 71-87.

Spear LP (2000). The adolescent brain and age-related behavioral manifestations. Neurosci Biobehav Rev 24: 417-463.

Ste-Marie PA, Shir Y, Rampakakis E, Sampalis JS, Karellis A, Cohen M et al (2016). Survey of herbal cannabis (marijuana) use in rheumatology clinic attenders with a rheumatologist confirmed diagnosis. Pain 157: 2792-2797.

Stinson FS, Ruan WJ, Pickering R, Grant BF (2006). Cannabis use disorders in the USA: prevalence, correlates and co-morbidity. Psychol Med 36: 1447-1460.

Strasser F, Luftner D, Possinger K, Ernst G, Ruhstaller T, Meissner W et al (2006). Comparison of orally administered cannabis extract and delta-9tetrahydrocannabinol in treating patients with cancer-related anorexia-cachexia syndrome: a multicenter, phase III, randomized, double-blind, placebo-controlled clinical trial from the Cannabis-In-Cachexia-Study-Group. I Clin Oncol 24: 3394-3400.

Substance Abuse and Mental Health Services Administration (2014a). Results from the 2013 National Survey on Drug Use and Health: summary of national findings. SAMHSA: Rockville, MD.

Substance Abuse and Mental Health Services Administration (2014b). The TEDS Report: Gender Differences in Primary Substance of Abuse across Age Groups. Rockville, MD.

Svendsen KB, Jensen TS, Bach FW (2004). Does the cannabinoid dronabinol reduce central pain in multiple sclerosis? Randomised double blind placebo controlled crossover trial. BMJ 329: 253.

Tseng A, Craft R (2001). Sex differences in antinociceptive and motoric effects of cannabinoids. Eur J Pharmacol 430: 41-47.

Tseng AH, Craft RM (2004). $\mathrm{CB}_{1}$ receptor mediation of cannabinoid behavioral effects in male and female rats. Psychopharmacology 172: 25-30.

Tseng A, Harding J, Craft R (2004). Pharmacokinetic factors in sex differences in Delta(9)tetrahydrocannabinol-induced behavioral effects in rats. Behav Brain Res 154: 77-83.

Ungerleider JT, Andrysiak T, Fairbanks L, Goodnight J, Sarna G, Jamison K (1982). Cannabis and cancer chemotherapy: a comparison of oral delta-9-THC and prochlorperazine. Cancer 50: 636-645.

Van Laere K, Goffin K, Casteels C, Dupont P, Mortelmans L, de Hoon J et al (2008). Gender-dependent increases with healthy aging of the human cerebral cannabinoid-type 1 receptor binding using $\left[{ }^{18} \mathrm{~F}\right] \mathrm{MK}-9470$ PET. Neuroimage 39: 1533-1541 An imaging study that focuses on markers of CB1 receptor availability as a function of sex and age.

Viveros MP, Llorente R, Suarez J, Llorente-Berzal A, López-Gallardo M, de Fonseca FR (2012). The endocannabinoid system in critical neurodevelopmental periods: sex differences and neuropsychiatric implications. I Psychopharmacol 26: 164-176.

Viveros MP, Marco EM, López-Gallardo M, Garcia-Segura LM, Wagner EJ (2011). Framework for sex differences in adolescent neurobiology: a focus on cannabinoids. Neurosci Biobehav Rev 35: 1740-1751.

Waissengrin B, Urban D, Leshem Y, Garty M, Wolf I (2015). Patterns of use of medical cannabis among Israeli cancer patients: a single institution experience. J Pain Symptom Manage 49: 223-230.

Wakley AA, Craft RM (2011). Antinociception and sedation following intracerebroventricular administration of $\Delta$-tetrahydrocannabinol in female vs. male rats. Behav Brain Res 216: 200-206.

Wakley AA, McBride AA, Vaughn LK, Craft RM (2014). Cyclic ovarian hormone modulation of supraspinal $\Delta^{9}$-tetrahydrocannabinol-induced antinociception and cannabinoid receptor binding in the female rat. Pharmacol Biochem Behav 124C: 269-277.

Wakley AA, Wiley JL, Craft RM (2014). Sex differences in antinociceptive tolerance to THC. Drug Alcohol Depend 143: 22-28 Demonstrates that loss of THC antinociceptive potency is greater in female than male rats - even though females were given $~ 30 \%$ less THC than males, to adjust for initially greater THC potency in females.

Wakley AA, Wiley JL, Craft RM (2015). Gonadal hormones do not alter the development of antinociceptive tolerance to delta-9-tetrahydrocannabinol in adult rats. Pharmacol Biochem Behav 133: 111-121.

Wall ME, Sadler BM, Brine D, Taylor H, Perez-Reyes M (1983). Metabolism, disposition, and kinetics of delta-9-tetrahydrocannabinol in men and women. Clin Pharmacol Ther 34: 352-363.

Wallace M, Schulteis G, Atkinoson JH, Wolfson T, Lazzaretto D, Bentley $H$ et al (2007). Dose-dependent effects of smoked cannabis on capsaicininduced pain and hyperalgesia in healthy volunteers. Anesthesiology 107: 785-796.

Wallace MS, Marcotte TD, Umlauf A, Gouaux B, Atkinson JH (2015). Efficacy of inhaled cannabis on painful diabetic neuropathy. J Pain 16: 616-627. 
Wang T, Collet J-P, Shapiro S, Ware MA (2008). Adverse effects of medical cannabinoids: a systematic review. Can Med Assoc J 178: 1669-1678.

Ware MA, Fitzcharles MA, Joseph L, Shir Y (2010). The effects of nabilone on sleep in fibromyalgia: results of a randomized controlled trial. Anesth Analg 110: 604-610.

Ware MA, Wang T, Shapiro S, Collet JPCOMPASS study team (2015). Cannabis for the Management of Pain: Assessment of Safety Study (COMPASS). J Pain 16: 1233-1242.

Washburn N, Borgquist A, Wang K, Jeffery GS, Kelly MJ, Wagner EJ (2013). Receptor subtypes and signal transduction mechanisms contributing to the estrogenic attenuation of cannabinoid-induced changes in energy homeostasis. Neuroendocrinology 97: 160-175.

Watanabe K, Matsunaga T, Narimatsu S, Yamamoto I, Yoshimura H (1992). Sex difference in hepatic microsomal aldehyde oxygenase activity in different strains of mice. Res Commun Chem Pathol Pharmacol 78: 373-376.

Web CW, Web SM (2014). Therapeutic benefits of cannabis: a patient survey. Hawaii J Med Pub Health 73: 109-111.

Weed PF, Filipeanu CM, Ketchum MJ, Winsauer PJ (2016). Chronic $\Delta^{9}-$ tetrahydrocannabinol during adolescence differentially modulates striatal CB1 receptor expression and the acute and chronic effects on learning in adult rats. $J$ Pharmacol Exp Ther 356: 20-31.

Whiting PF, Wolff RF, Deshpande S, Di Nisio M, Duffy S, Hernandez AV et al (2015). Cannabinoids for medical use: a systematic review and meta-analysis. JAMA 313: 2456-2473.

Wiers CE, Shokri-Kojori E, Wong CT, Abi-Dargham A, Demiral ŞB, Tomasi D et al (2016). Cannabis abusers show hypofrontality and blunted brain responses to a stimulant challenge in females but not in males. Neuropsychopharmacology 41: 2596-2605 This study explored metabolic brain responses after placebo and methylphenidate administration in male and female cannabis users matched for current cannabis use compared to healthy controls.

Wiley JL (2003). Sex-dependent effects of $\Delta^{9}$-tetrahydrocannabinol on locomotor activity in mice. Neurosci Lett 352: 77-80.

Wiley JL, Burston JJ (2014). Sex differences in $\Delta^{9}$-tetrahydrocannabinol metabolism and in vivo pharmacology following acute and repeated dosing in adolescent rats. Neurosci Lett 576: 51-55 Demonstrates higher brain and blood levels of the major active metabolite 11-OH-THC in female compared to male, adolescent and adult rats; sex differences are greater after chronic THC administration than after acute THC administration.
Wiley JL, Evans RL (2009). To breed or not to breed? Empirical evaluation of drug effects in adolescent rats. Int J Dev Neurosci 27: 9-20.

Wiley JL, Lefever TW, Marusich JA, Craft RM (2017). Comparison of the discriminative stimulus and response rate effects of $\Delta^{9}$-tetrahydrocannabinol and synthetic cannabinoids in female and male rats. Drug Alcohol Depend 172: 51-59.

Wiley JL, O'Connell MM, Tokarz ME, Wright MJ (2007). Pharmacological effects of acute and repeated administration of delta9-tetrahydrocannabinol in adolescent and adult rats. J Pharmacol Exp Ther 320: 1097-1105.

Wiley JL, Walentiny DM, Vann RE, Baskfield CY (2011). Dissimilar cannabinoid substitution patterns in mice trained to discriminate $\Delta^{9}$-tetrahydrocannabinol or methanandamide from vehicle. Behav Pharmacol 22: 480-488.

Wilsey B, Marcotte TD, Deutsch R, Zhao H, Prasad H, Phan A (2016). An exploratory human laboratory experiment evaluating vaporized cannabis in the treatment of neuropathic pain from spinal cord injury and disease. $J$ Pain 17: 982-1000.

Winsauer PJ, Daniel JM, Filipeanu CM, Leonard ST, Hulst JL, Rodgers SP et al (2011). Long-term behavioral and pharmacodynamic effects of delta-9tetrahydrocannabinol in female rats depend on ovarian hormone status. Addict Biol 16: 64-81.

Winsauer PJ, Filipeanu CM, Bailey EM, Hulst JL, Sutton JL (2012). Ovarian hormones and chronic administration during adolescence modify the discriminative stimulus effects of delta-9-tetrahydrocannabinol $\left(\Delta^{9}-\mathrm{THC}\right)$ in adult female rats. Pharmacol Biochem Behav 102: 442-449.

Winsauer PJ, Sutton JL (2014). Chronic administration during early adulthood does not alter the ormonally-dependent disruptive effects of delta-9-tetrahydrocannabinol $\left(\Delta^{9}-\mathrm{THC}\right)$ on complex behavior in female rats. Pharmacol Biochem Behav 117: 118-127.

Xing G, Carlton J, Zhang L, Jiang X, Fullerton C, Li H et al (2011). Cannabinoid receptor expression and phosphorylation are differentially regulated between male and female cerebellum and brain stem after repeated stress: Implication for PTSD and drug abuse. Neurosci Lett 502: 5-9.

Yamagata K, Sugimura M, Yoshida M, Sekine S, Kawano A et al (2016). Estrogens exacerbate nociceptive pain via up-regulation of TRPV1 and ANO1 in trigeminal primary neurons of female rats. Endocrinology 157: 4309-4317. 